Article

\title{
Experimental Investigation and Benchmark Study of Oxidation of Methane-Propane-n-Heptane Mixtures at Pressures up to 100 Bar
}

\author{
Sebastian Schuh ${ }^{1, *}$, Ajoy Kumar Ramalingam ${ }^{2}$, Heiko Minwegen ${ }^{2}$, Karl Alexander Heufer ${ }^{2}$ \\ and Franz Winter ${ }^{1}$ (I) \\ 1 Institute of Chemical, Environmental and Bioscience Engineering, TU Wien, Getreidemarkt 9/166, \\ 1060 Vienna, Austria \\ 2 Physico-Chemical Fundamentals of Combustion (PCFC), RWTH University, Aachen, Schinkelstraße 8, \\ 52062 Aachen, Germany \\ * Correspondence: sebastian.schuh@tuwien.ac.at
}

Received: 9 July 2019; Accepted: 30 August 2019; Published: 4 September 2019

\begin{abstract}
Dual fuel combustion exhibits a high degree of complexity due to the presence of different fuels like diesel and natural gas in initially different physical states and a spatially strongly varying mixing ratio. Optimizing this combustion process on an engine test bench is costly and time consuming. Cost reduction can be achieved by utilizing simulation tools. Although these tools cannot replace the application of test benches completely, the total development costs can be reduced by an educated combination of simulations and experiments. A suitable model for describing the reactions taking place in the combustion chamber is required to correctly reproduce the dual fuel combustion process. This is why in the presented study, four different reaction mechanisms are benchmarked to shock tube (ST) and rapid compression machine (RCM) measurements of ignition delay times (IDTs) at pressures between 60 and 100 bar and temperatures between 671 and $1284 \mathrm{~K}$. To accommodate dual fuel relevant diesel-natural gas mixtures, methane-propane-n-heptane mixtures are considered as the surrogate. Additionally, the mechanisms AramcoMech 1.3, 2.0 and 3.0 are tested for methane-propane mixtures. The influence of pressure and propane/n-heptane content on the IDT based on the measurements is presented and the extent to which the mechanisms can reflect the IDT-changes discussed.
\end{abstract}

Keywords: methane-propane-n-heptane mixtures; dual fuel concept; rapid compression machine; shock tube; ignition delay time

\section{Introduction}

In the transport sector on land or sea, compression-ignition engines play the dominant role due to their proven economy, robustness and reliability [1]. Due to the growing stringent environmental directives such as Euro VI for commercial vehicles and Tier II/Tier III for the maritime sector, more sophisticated engine concepts and additional technologies such as urea injection [2] are needed to meet the limits. One approach to reduce pollutant emissions caused by compression-ignition engines could be the operation in dual fuel mode. Here, a gas-air mixture is fed into the combustion chamber and ignited by the injection of a diesel pilot jet [3]. Compared to a conventional diesel engine, the nitrogen oxide $\left(\mathrm{NO}_{\mathrm{x}}\right)$ and sulfur oxide $\left(\mathrm{SO}_{\mathrm{x}}\right)$ content can be significantly reduced [3]. In order to further optimize the dual fuel engine efficiency and to keep the emission of pollutants as low as possible, it is necessary to develop a profound understanding of the combustion processes in the combustion chamber. Since experimental testing on an engine test bench involves high cost and time, it is desirable to support the engine development by a theoretical model capable of simulating the dual fuel combustion process. 
Furthermore, because of the injection of a diesel jet into a gaseous fuel-air mixture, this model should accurately reproduce the physical and chemical combustion processes in both the diesel-lean and the diesel-rich region. Therefore, knowledge of the physical and the chemical processes are necessary foundations for the simulations. To address the understanding of the chemical processes, the identification of suitable detailed kinetic models is necessary. This motivates this study to benchmark different detailed kinetic mechanisms available in the literature at dual fuel engine relevant conditions.

Since diesel fuel is a complex mixture of thousands of hydrocarbon compounds with carbon numbers between 6 and 28 [4], detailed kinetic models containing all relevant species are often not available. Therefore, it is convenient to define a surrogate fuel, which is capable to represent the overall combustion behavior of a general diesel fuel. For dual fuel investigations, $n$-heptane is a frequently found diesel surrogate in the literature [5-13]. In most of these studies, natural gas is approximated by methane. In order to better map the methane number of natural gas, propane and ethane are often added to methane [10,13-16]. For this reason, and to understand the effect of the admixtures of methane and propane in the presented study, n-heptane was used as a diesel surrogate, and natural gas was approximated by methane-propane mixtures.

\section{Materials and Methods}

\subsection{Investigated Reaction Mechanisms}

For the investigations of the dual fuel relevant combustion processes, the simulations must be capable of correctly mapping the ignition and combustion characteristics of the surrogate components. Four different reaction mechanisms are selected that include a carbon number space of hydrocarbons up to C7. The first in this work tested mechanism was developed for the simulation of $n$-heptane oxidation, and released in 2012 by Mehl et al. [17]. The core structure of the mechanism is based on detailed C1-C4 oxidation pathways. Additional pathways of saturated and non-saturated linear and branched hydrocarbons up to $\mathrm{C} 7$, and aromatic structures are included to reflect the combustion chemistry of the larger hydrocarbons. The mechanism was validated in experiments in shock tubes (STs) and rapid compression machines (RCMs) at pressures between 3 and 50 bar, temperatures from 650 to $1200 \mathrm{~K}$ and stoichiometric fuel/air mixtures. The second used mechanism, published by Cai et al. [18] in 2015, was optimized for gasoline surrogate fuels. A primary reference fuels (PRF) model based on the mechanism of Curran et al. [19] was combined with the mechanism for $\mathrm{C} 0-\mathrm{C} 8$ hydrocarbons and various substituted aromatic species of Narayanaswamy et al. [20]. Furthermore, the mechanism for ethanol oxidation of $\mathrm{Li}$ et al. [21] and the mechanism for $\mathrm{NO}_{\mathrm{x}}$-formation of Lamoureux et al. [22] was included. Cai et al.'s mechanism was validated against ignition delay times (IDTs) measured at a pressure of up to $55 \mathrm{bar}$, high pressure laminar flame speeds of up to $25 \mathrm{bar}$, as well as species profiles of PRF mixtures and ternary mixtures consisting of n-heptane, iso-octane and toluene at pressures up to 12.5 bar. The third tested mechanism was published in 2016 by Zhang et al. [23]. The mechanism originates from the mechanism of Mehl et al. [17], with the updated base chemistry for C1-C4 species taken from AramcoMech 2.0 [24]. Furthermore, updated sub mechanisms of the three pentane isomers published by Bugler et al., and for n-hexane are included [25-27]. This mechanism was validated against IDTs measured in STs at pressures up to 55 bar, species profiles from a jet-stirred reactor and laminar flame speeds of n-heptane at pressures up to 10 bar. The fourth mechanism used for testing, published in 2018 by Huang et al. [14], was specifically developed for the simulation of dual fuel engine combustion and the prediction of emissions. It includes, in addition to sub mechanisms for the description of n-butylbenzene and natural gas, an n-heptane mechanism based on the reduced PRF mechanism of Wang et al. [28]. The n-butylbenzene and partly the natural gas sub mechanism are obtained through combination of the alkyl-aromatic sub mechanism of Darcy et al. [29] and the C1-C4 reaction mechanism AramcoMech 1.3 [30]. The natural gas sub mechanism is further including pathways from Healy et al. [31]. For consideration of aromatic species, the mechanism of Narayanaswamy et al. [20] is also included. Further soot formation pathways from the PAH sub mechanism developed by 
Wang et al. [32] and $\mathrm{NO}_{x}$-formation pathways from a simple $\mathrm{NO}_{\mathrm{x}}$-mechanism [33] are included as well. For validation, IDTs at pressures up to 50 bar of n-heptane and n-butylbenzene mixtures were used. Furthermore, the mechanism is validated against experimental flame speeds of n-heptane, n-butylbenzene and methane at pressures of up to 60 bar.

In addition to the four mechanisms mentioned above, the three versions of the AramcoMech reaction mechanism are considered in this study for methane-propane mixtures without n-heptane addition. These are detailed mechanisms for characterizing the kinetic and thermochemical properties of a large number of hydrocarbons and oxygenated fuels with a carbon number of 1 to 4 . The mechanisms were developed by the Combustion Chemistry Center at NUI Galway and validated against experimental measurements including data from ST, RCM, different flames and flow reactors. In this study, simulations were performed with AramcoMech 1.3 (released 2013; considering 253 species and 1542 reactions) [30], AramcoMech 2.0 (released 2016; considering 493 species and 2716 reactions) [24] and AramcoMech 3.0 (released 2018; considering 581 species and 3037 reactions) [34].

All simulations were performed with the software LOGEresearch, version LSv1.09 [35]. The constant volume (CV) simulations were performed with the CV module of LOGEresearch at specified initial conditions, like pressure, temperature and simulation time. IDTs are defined in comparison to the experiments either at the point of maximum rise of pressure or activated $\mathrm{CH}$ (denoted as $\mathrm{CH}^{*}$ or $\mathrm{CHV}$ in the different mechanism).

To simulate the IDTs that were experimentally determined with the RCM, in LOGEresearch the reactor module "rapid compression machine" was used. As input parameter the homogeneous fuel-air mixture, the starting pressure and the starting temperature of the simulated experimental condition was defined. The machine-specific compression of the mixture was taken into account by considering the effective volume profile derived from the pressure profile of the associated non-reactive RCM measurement as described later in Section 2.2.

For simulations of the IDTs of the ST measurements, the "rapid compression machine" reactor module was applied, too. In contrast to the RCM simulation, the starting pressure and starting temperature were defined as the pressure and temperature value that were reached in the ST after the shock wave reflection. In the simulation, the ST facility effects are then taken into account by a facility-specific pressure increase over time, which is converted into an effective volume profile. A more detailed description of the RCM and ST facility effects and the calculation of the effective volume profile can be found in the following chapter.

\subsection{Experiments}

Compression pressures for large dual fuel engines as used for maritime or off-road applications can be above 50 bar [36]. This application-relevant pressure regime motivates this study to carry out the experimental ignition properties of methane-propane mixtures and methane-propane-n-heptane mixtures at compression pressure values between 60 and $100 \mathrm{bar}$. The detailed experimental conditions and a test series overview are given in Table 1. The combination of an ST and an RCM gives the opportunity to take out the measurements over a wide temperature range of 671 to $1284 \mathrm{~K}$. The methane-propane mixture, representing the natural gas background in a dual fuel engine, is chosen so that an air-fuel ratio of 1.9 is reached. Depending on the amount of admixed n-heptane, the global air-fuel ratio varies between 1.226 and 1.9. Additionally to the experimental data from this study, from a previous study where the ignitability of methane-propane mixtures at high pressures was already investigated by Pachler et al. [37], results have also been considered here to benchmark the reaction mechanisms (test series RCM1.1, RCM1.2 and RCM1.3 in Table 1). 
Table 1. Experimental test matrix of ignitability investigations with a rapid compression machine (RCM) and a shock tube (ST).

\begin{tabular}{|c|c|c|c|c|c|c|c|}
\hline \multirow{2}{*}{ Test Facility } & \multirow{2}{*}{ Test Series } & \multicolumn{3}{|c|}{ Fuel Composition } & \multirow{2}{*}{$\begin{array}{c}\text { Pressure } \\
\text { (bar) }\end{array}$} & \multirow{2}{*}{$\begin{array}{c}\text { Temperature } \\
\text { (K) }\end{array}$} & \multirow[t]{2}{*}{ Reference } \\
\hline & & $\begin{array}{c}\mathrm{CH}_{4} \\
(\mathrm{~mol} \%)\end{array}$ & $\begin{array}{c}\mathrm{C}_{3} \mathrm{H}_{8} \\
(\mathrm{~mol} \%)\end{array}$ & $\begin{array}{c}\mathrm{x}_{\mathrm{n}-\mathrm{C}_{7} \mathrm{H}_{16}} \\
\text { Defined } \\
\text { by (1) }\end{array}$ & & & \\
\hline \multirow{8}{*}{$\begin{array}{c}\text { Rapid } \\
\text { compression } \\
\text { machine }\end{array}$} & RCM1.1 & 100 & 0 & - & 100 & $906-941$ & [37] \\
\hline & RCM1.2 & 95 & 5 & - & 100 & $888-916$ & [37] \\
\hline & RCM1.3 & 70 & 30 & - & 100 & $826-865$ & [37] \\
\hline & RCM2.1 & 90 & 10 & - & 100 & $803-898$ & this study \\
\hline & RCM2.2 & 95 & 5 & 0.025 & 60 & $701-877$ & this study \\
\hline & RCM2.3 & 95 & 5 & 0.05 & 60 & $671-781$ & this study \\
\hline & RCM2.4 & 95 & 5 & 0.025 & 100 & $709-817$ & this study \\
\hline & RCM2.5 & 100 & 0 & 0.025 & 60 & $720-869$ & this study \\
\hline \multirow{2}{*}{ Shock tube } & ST1.1 & 95 & 5 & 0.1 & 60 & $748-1187$ & this study \\
\hline & ST1.2 & 100 & 0 & 0.1 & 60 & $785-1284$ & this study \\
\hline
\end{tabular}

The IDTs for methane-propane-n-heptane mixtures from this study were measured in the RCM [38,39] and the ST [23] at PCFC (Physico-Chemical Fundamentals of Combustion), RWTH Aachen University. The reaction chamber of the RCM, the driven section of the ST and their corresponding mixing vessels along with the tubing are electrically heated to accommodate low vapor pressure fuels. The initial temperature is monitored by type " $\mathrm{T}$ " thermocouples mounted on the reaction chamber of the RCM and the driven section of the ST. The fuel-air mixtures were prepared with the aid of two static pressure sensors (STS 1st 0 to $500 \mathrm{mbar}$ (RCM, ST), STS 1 st 0 to 5 bar (RCM) and STS 1 st 0 to 10 bar (ST)), which monitored the partial pressures required for the mixtures. The dynamic pressure changes in the reaction chamber of the RCM and the driven section of the ST were recorded with the help of PCB 113B22 sensors. Additionally, for these high-pressure experiments, the pressure time history for non-reactive mixtures in the RCM was determined using a Kistler 6125C pressure sensor along with the PCB for correcting the compressed pressure and quantifying the effect of the thermal shock. The details of this procedure are given in [40]. The compressed temperature in the RCM was calculated using the adiabatic compression and expansion routine of Gaseq [41]. The reflected shock conditions were calculated using an in-house code based on the shock and detonation toolbox [42] routines implemented for Cantera [43]. The typical pressure trace obtained from both the RCM and ST is shown in Figures 1 and 2, respectively. The uncertainty in the compressed temperature in the RCM is estimated to be $\pm 5 \mathrm{~K}$ [40]. In the ST the uncertainty in the reflected shock temperature and pressure is estimated to be $0.7 \%(\mathrm{~K})$ and $1.5 \%$ (bar), respectively. For the uncertainty estimation in the ST, possible uncertainties in the measurements of initial temperatures and pressures, the shock velocities and the thermodynamic data are taken into account. A detailed description of the approach is available in [44]. The observed variation in the IDT on the RCM amounts to be $10 \%$ and the uncertainty of the IDT measurements in the ST is assumed to be within $20 \%$, which is on par with other similar facilities [45].

As seen in Figure 1, the RCM pressure profile shows a compression phase and a post compression phase with a pressure drop due to heat loss. Both these facility-dependent effects compete against each other in the time scales of the RCM. On the one hand, for the short IDTs measured in the $\mathrm{RCM}$, the radical pool generation during the compression phase dominates the heat loss effects and reduces the IDTs compared to an ideal constant volume reactor. On the other hand, for the long IDTs, the heat loss effect overlooks the effect of radical pool generation and increases the IDT. Therefore, it is necessary to include both the compression and heat loss phase during the simulation in order to capture the facility effects accurately [46]. This typically is done with the help of the corresponding non-reactive experiment, where the oxygen content is replaced by nitrogen in the mixture composition. The non-reactive pressure profile is then converted into an effective volume profile using isentropic relations and is further used as an input during simulations $[38,45]$. 


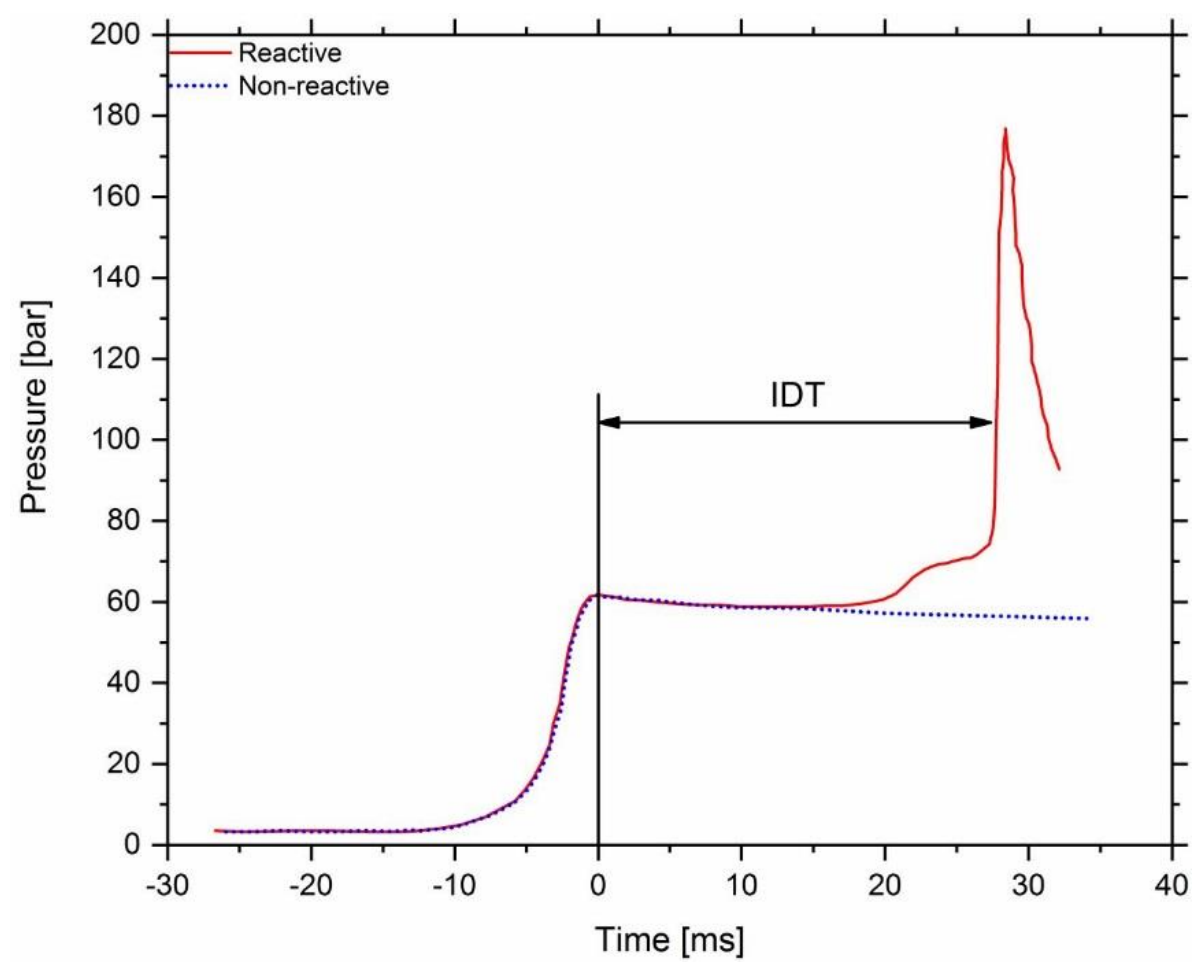

Figure 1. Pressure-time history of an experiment in the RCM. The definition of the ignition delay time (IDT), the reactive and the non-reactive pressure traces are shown.

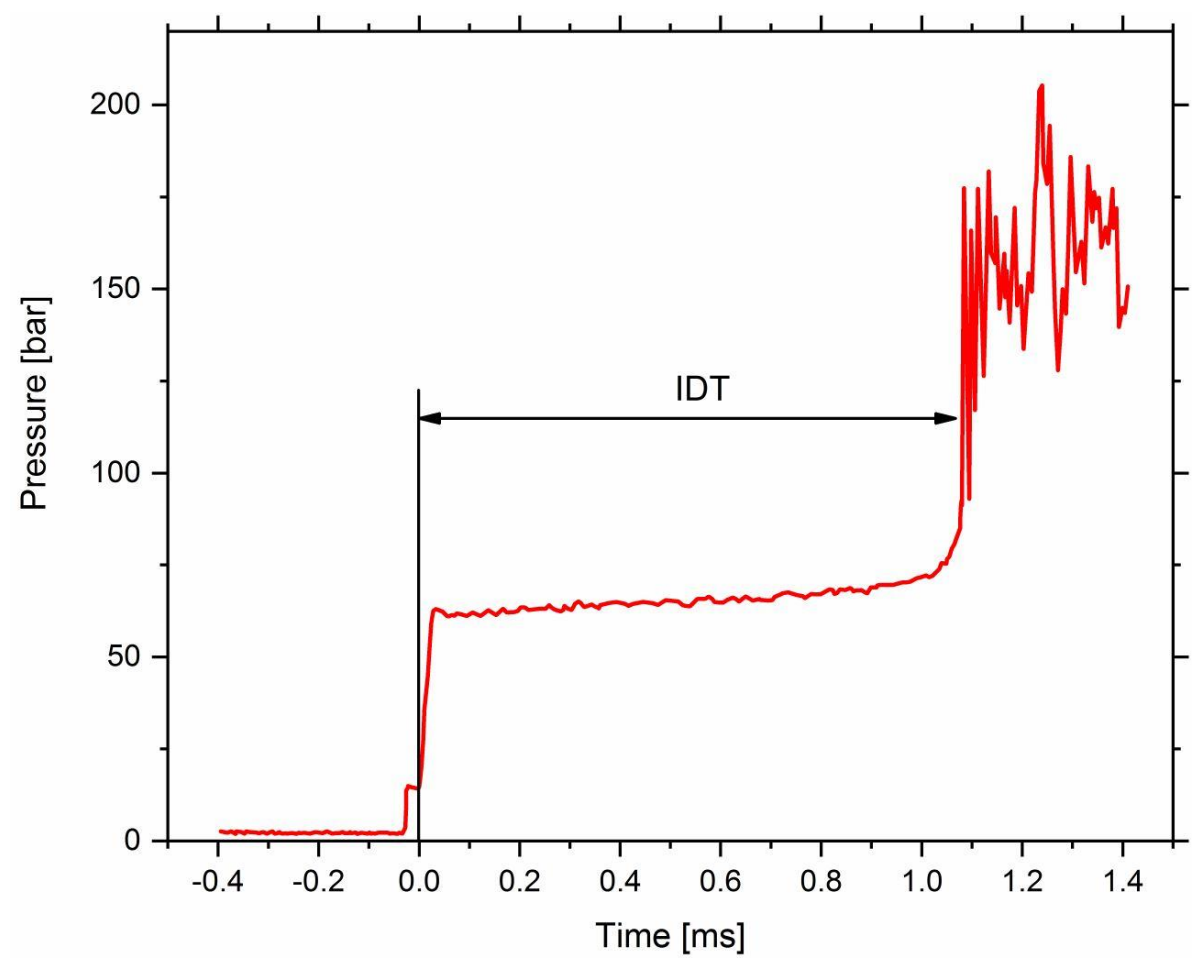

Figure 2. Pressure-time history of an experiment in the ST. The definition of the IDT is shown.

A detailed explanation of the above-mentioned facility effects is described in the work of Sung and Curran [46]. The non-reactive pressure profiles are available online in Supplementary Materials. The ST also shows a non-ideal behavior at longer IDTs due to the boundary layers and non-ideal opening of the diaphragms which constitute to a constant rate of pressure rise at the reflected shock 
conditions as a function of time (dp/dt) [47,48]. The constant pressure rise leads to a temperature increase, thereby reducing the IDT from its ideal behavior. The ST used in this study showed an average pressure increase of $8 \% / \mathrm{ms}$, which was taken into account in the simulations of the IDT.

\section{Results and Discussion}

In the following sections, the effect of n-heptane and propane-addition on the IDT will be discussed in detail, as well as accounting for the pressure dependence seen in the ignition process. In the respective sections, the extent to which the above-mentioned reaction mechanisms can mimic the measured behavior also is investigated. In Figure 3 an overview of the RCM and ST results is given. The results are available online in Supplementary Materials.

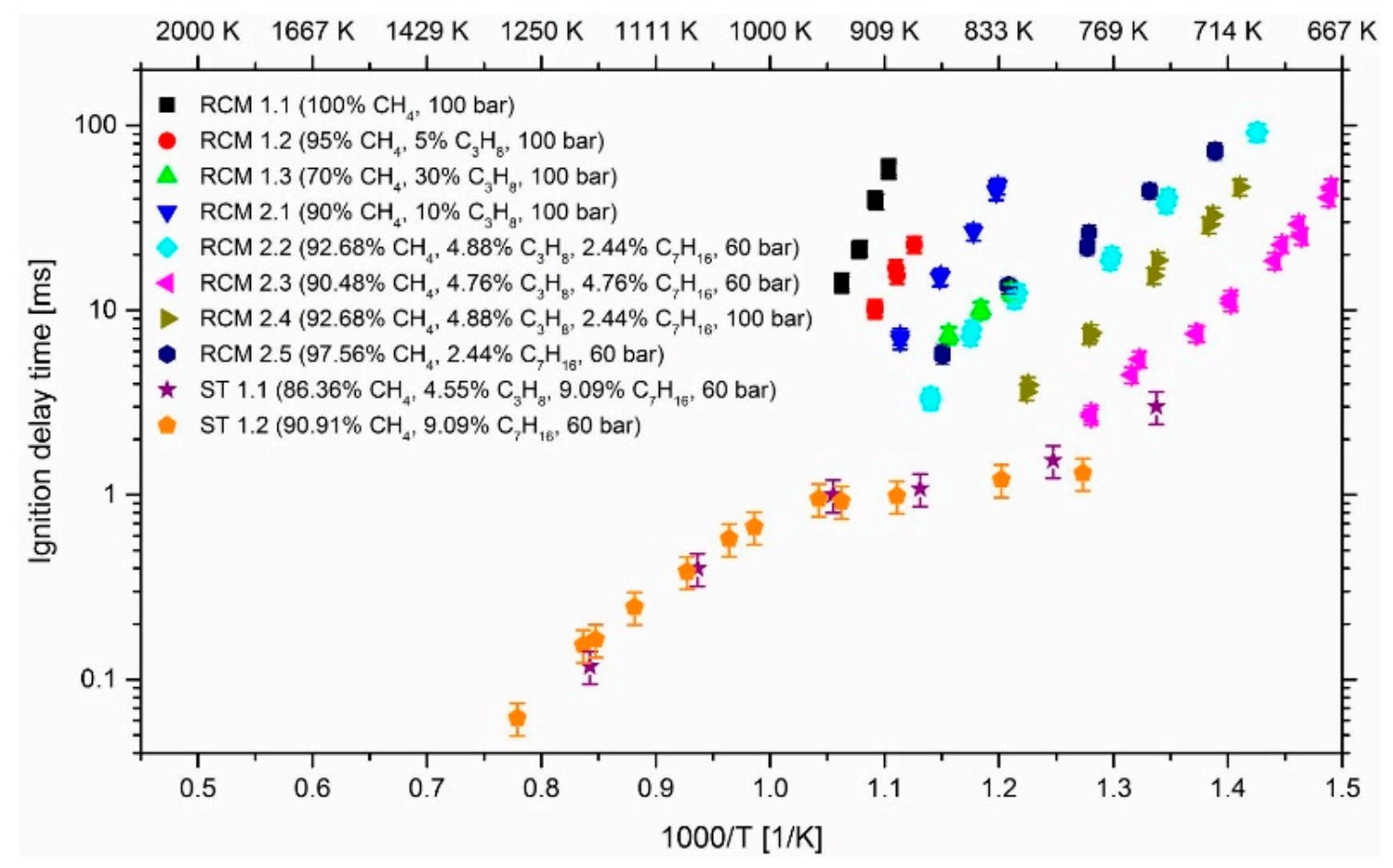

Figure 3. Measured IDTs from the RCM and ST (this study and [37]).

Both the addition of propane and the addition of n-heptane leads to a significant reduction of the IDT compared to the neat methane case. As already theoretically investigated in a previous study [49], the reducing effect of $n$-heptane is more pronounced compared to propane considering equal admixture quantities. The dominant impact of n-heptane on the IDT compared to propane is also evident in the ST data, where the measured IDT for the methane-propane-n-heptane mixtures (86.3 mol \%-4.6 mol \%-9.1 mol \% (ST1.1) and $90.9 \mathrm{~mol} \%-0 \mathrm{~mol} \%-9.1 \mathrm{~mol} \%$ (ST1.2)) shows hardly any difference within the measuring uncertainties.

\subsection{Effect of Propane}

In the above-mentioned work from Pachler et al. [37], the influence of the ignition properties of propane addition to methane was investigated for mixture ratios of $100 \mathrm{~mol} \%$ methane, $95 \mathrm{~mol} \%$ methane $-5 \mathrm{~mol} \%$ propane, and $70 \mathrm{~mol} \%$ methane- $-30 \mathrm{~mol} \%$ propane experimentally and by simulation using the reaction mechanism AramcoMech 1.3. To this data, in the present study the gas composition of $90 \mathrm{~mol} \%$ methane- $10 \mathrm{~mol} \%$ propane was added to achieve an improved coverage of experimental conditions. For further discussion, the measurement results of the IDTs against the inverse of the compressed gas temperature are shown in Figures 4-7 along with the simulated IDTs in the current 
benchmark study. Those results presented are performed at an air-fuel ratio of 1.9 and an end of compression pressure $P_{c}$ of 100 bar.

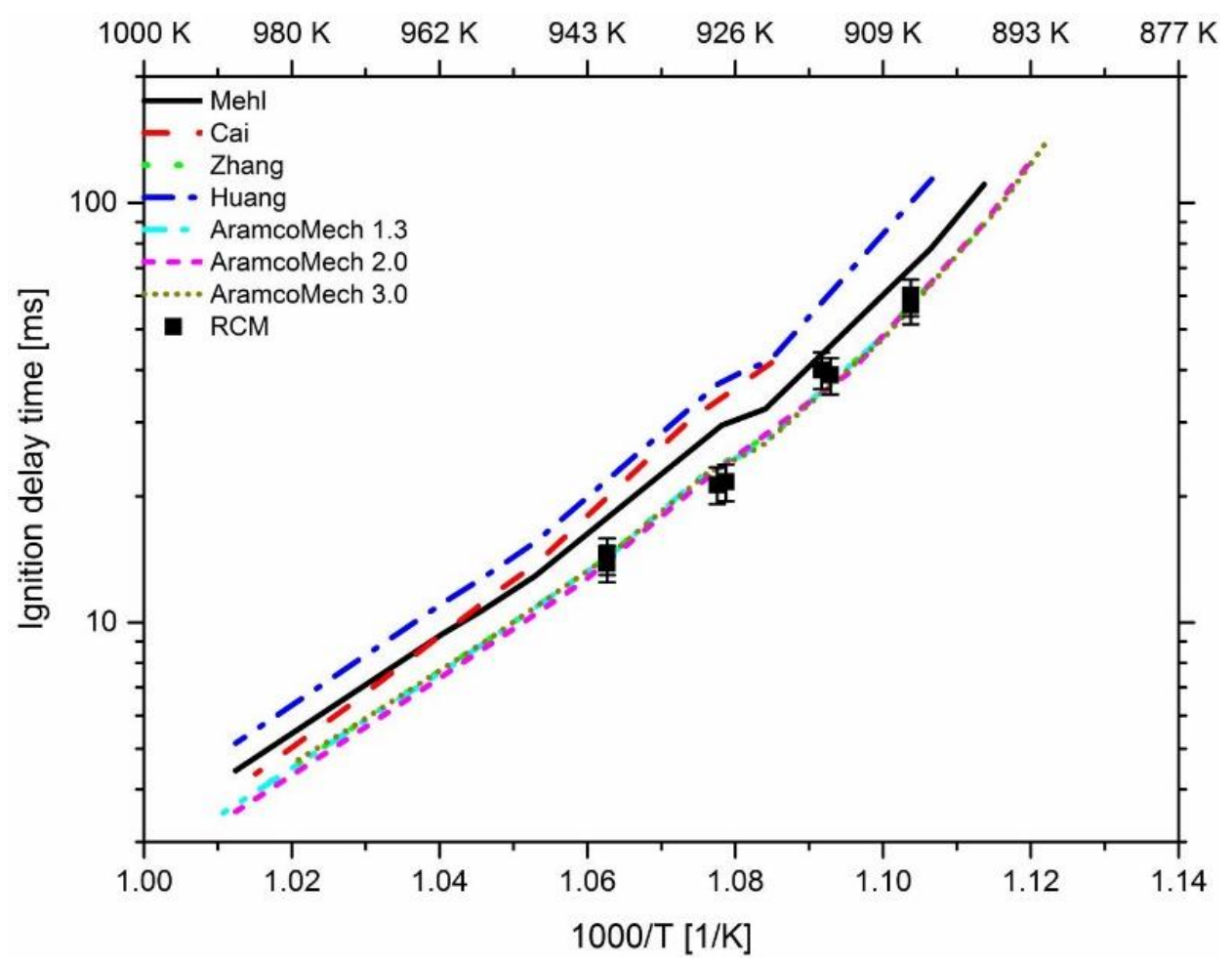

Figure 4. Experimental RCM data (symbols) [37] versus model prediction at $\mathrm{P}_{\mathrm{c}}=100$ bar using $100 \mathrm{~mol} \% \mathrm{CH}_{4}$ at $\lambda=1.9$.

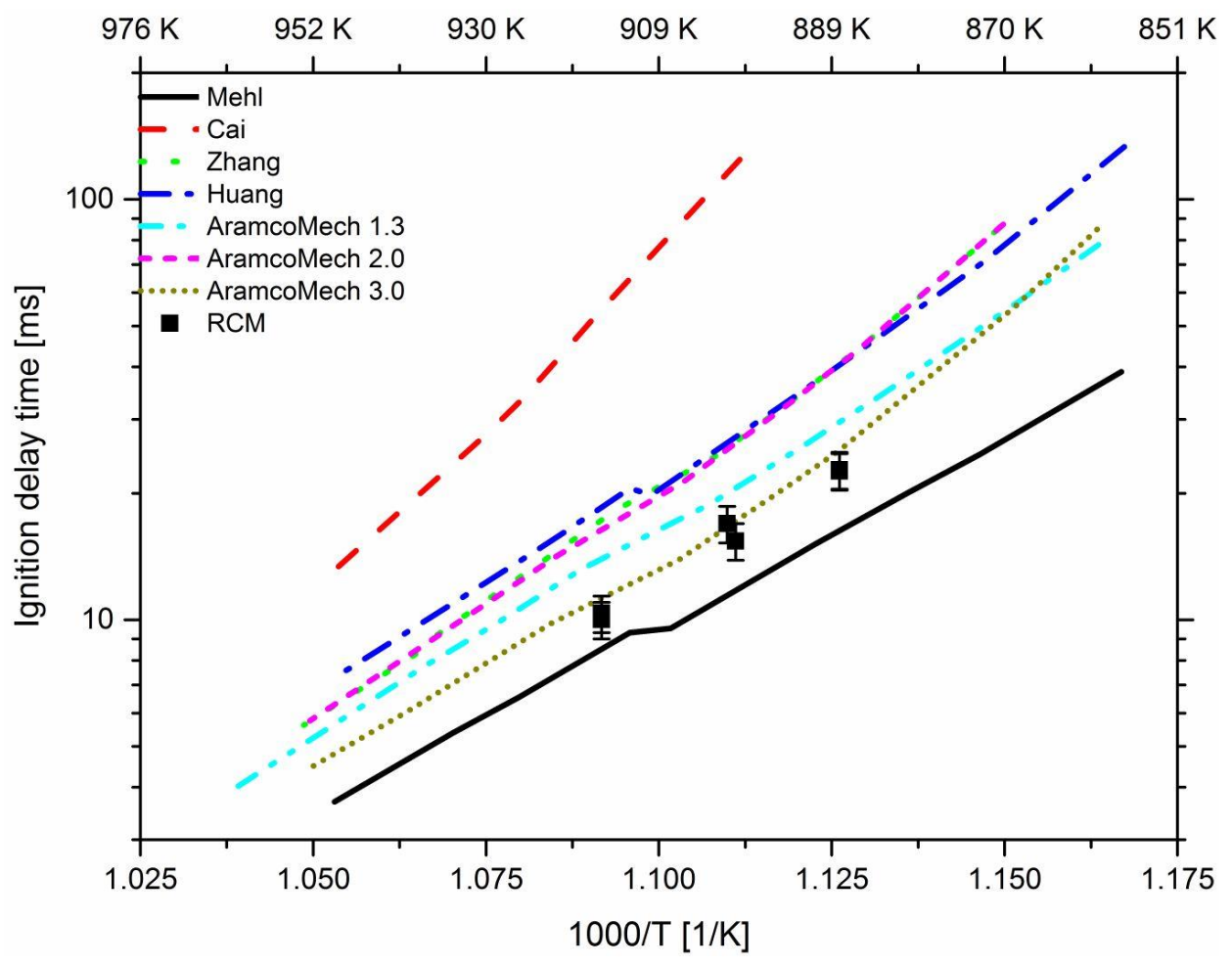

Figure 5. Experimental RCM data (symbols) [37] versus model prediction at $\mathrm{P}_{\mathrm{c}}=100 \mathrm{bar}$ using $95 \mathrm{~mol} \%$ $\mathrm{CH}_{4}$ and $5 \mathrm{~mol} \% \mathrm{C}_{3} \mathrm{H}_{8}$ at $\lambda=1.9$. 


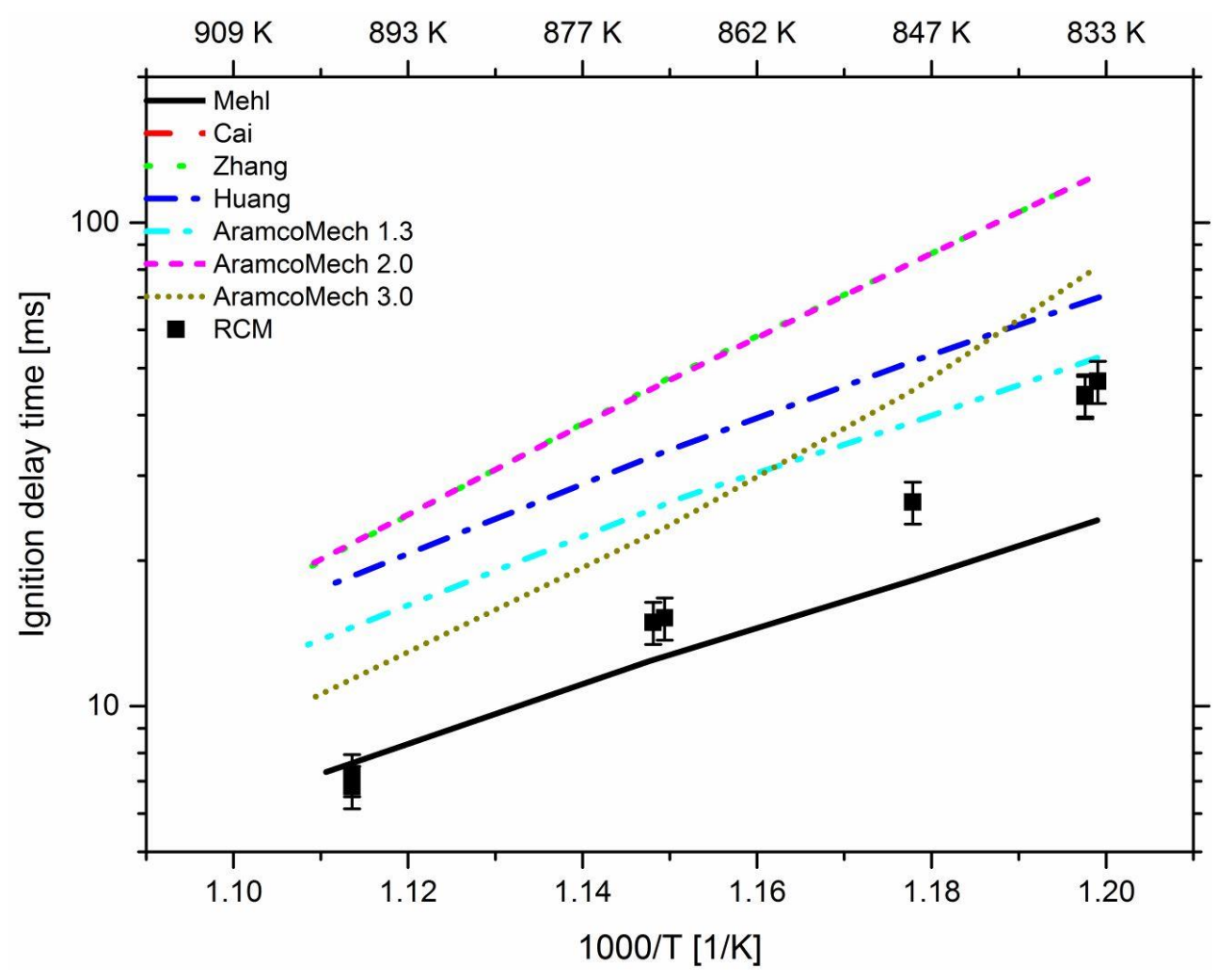

Figure 6. Experimental RCM data (symbols) versus model prediction at $\mathrm{P}_{\mathrm{c}}=100$ bar using $90 \mathrm{~mol} \%$ $\mathrm{CH}_{4}$ and $10 \mathrm{~mol} \% \mathrm{C}_{3} \mathrm{H}_{8}$ at $\lambda=1.9$.

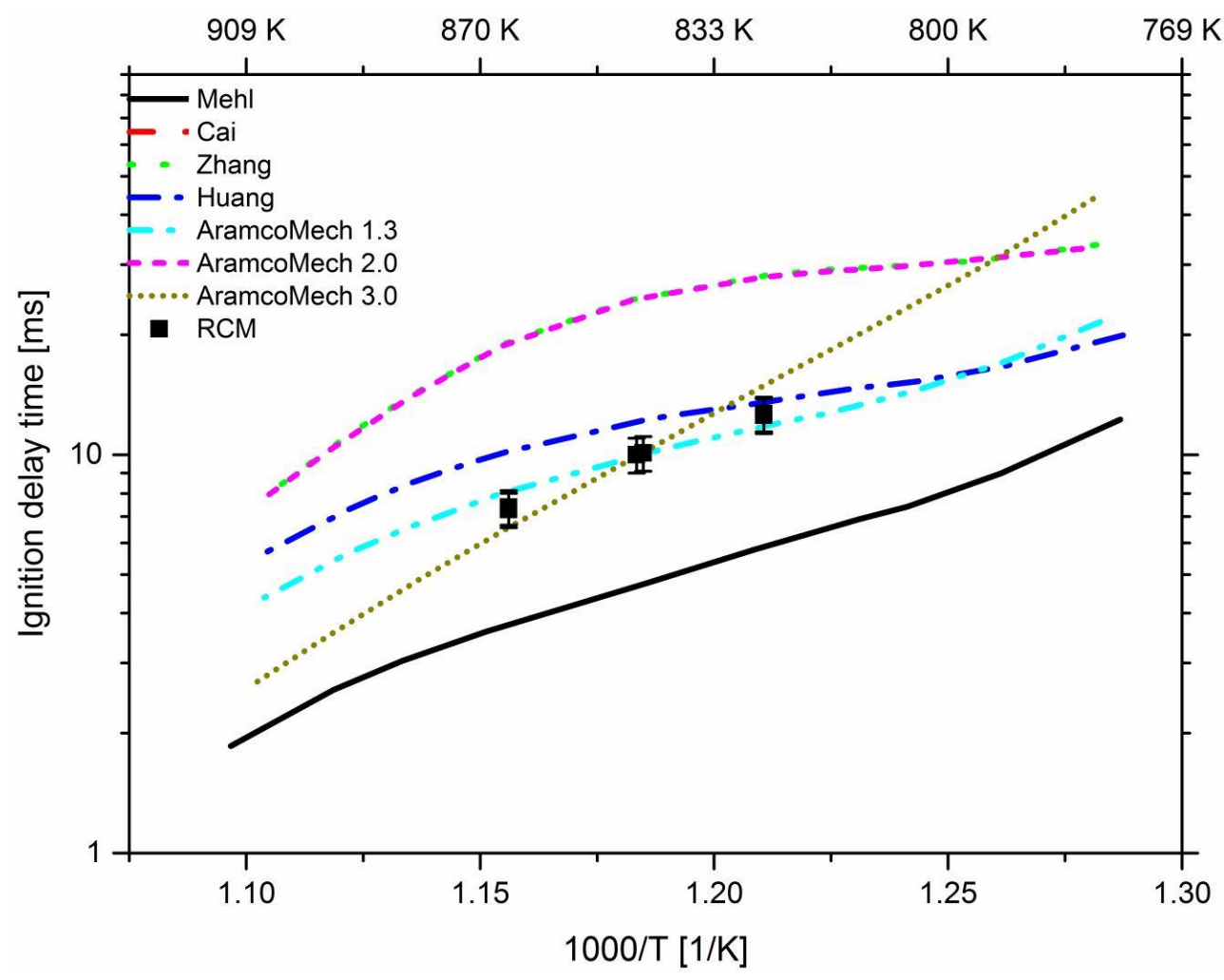

Figure 7. Experimental RCM data (symbols) [37] versus model prediction at $\mathrm{P}_{\mathrm{c}}=100 \mathrm{bar}$ using $70 \mathrm{~mol} \%$ $\mathrm{CH}_{4}$ and $30 \mathrm{~mol} \% \mathrm{C}_{3} \mathrm{H}_{8}$ at $\lambda=1.9$. 
Like it is mentioned above, the higher the proportion of propane in the methane-propane mixture, the shorter is the resulting IDT. At the considered temperature conditions, this behavior could be explained through the pronounced low temperature chemistry pathways of propane [50], increasing the reactivity compared to neat methane oxidation behavior.

Assessing the simulation results, a good match between the experimental results and the calculated IDTs using the AramcoMech 1.3 and 3.0 mechanism can be found for the methane-propane mixtures. In contrast, AramcoMech 2.0 shows an increasing overestimation of the IDTs with increasing propane content, reaching an average overestimation of about $130 \%$ at $30 \mathrm{~mol} \%$ propane content. The same behavior can be observed with the mechanism of Zhang, which is obvious since AramcoMech 2.0 is included in Zhang's mechanism. The mechanism of Huang exhibits an overestimating behavior, too. The calculated IDTs for pure methane are about $65 \%$ larger compared to the experimental values. For the methane-propane mixture with $30 \mathrm{~mol} \%$ propane addition, an average deviation of a bit more than $20 \%$ can be determined. The mechanism of Cai et al. shows a strong underestimated influence on the IDT-reducing effect of propane. This can be expected, since the Cai et al. mechanism does not include subsequent pathways of the 2 nd $_{2}$ addition and therefore no low temperature chain branching, which promotes the reactivity in this regime, can occur. This limits the simulation possibilities, because already at a propane content of $10 \mathrm{~mol} \%$, the predicted IDTs exceed the simulation time in the limits of the RCM non-reactive pressure time histories. As a consequence, no results are shown in Figures 6 and 7 presenting the results of a larger propane content than $10 \mathrm{~mol} \%$. Only the mechanism of Mehl et al. of the investigated mechanisms predicts an overestimation of the IDT-reducing effect of propane addition, leading to shorter IDTs compared to the measurements.

At $30 \mathrm{~mol} \%$ propane admixed, within the region of the experimental temperatures AramcoMech 1.3 and 3.0 show similar reactivity in agreement to the experimental values, although AramcoMech 3.0 shows a larger slope and, therefore, overall activation energy compared to the results of the other mechanisms. For a further comparison at a different temperature range, experimental IDTs from Petersen et al. [51] of methane-propane mixtures measured in an ST are available. With this data it is possible to compare the results of AramcoMech 1.3 and 3.0 directly at similar gas mixtures like in the study of Pachler et al. [37], consisting of $70 \mathrm{~mol} \%$ methane and $30 \mathrm{~mol} \%$ propane $(\phi=1$, $\sim 30$ bar, $1190-1503 \mathrm{~K}$ ) and $60 \mathrm{~mol} \%$ methane and $40 \mathrm{~mol} \%$ propane $(\phi=0.5,24-28$ bar, $1042-1296$ K). In Petersen's work, no device-specific pressure increase after shock wave reflection in the ST is given. Due to the similar build-up of a ST described in [48], simulations were carried out with a pressure increase of $4 \% / \mathrm{ms}$ stated there. In addition, the simulations are also performed without taking a pressure increase into account.

When comparing the simulation results with the experimental data from Peterson et al., as shown in Figure 8, it can be found that the IDT-values calculated with the AramcoMech 3.0 mechanism are closer to the experimental data with an average absolute deviation of $18 \%$ in the temperature range from 1040 to $1280 \mathrm{~K}$, compared to an average absolute deviation of $34 \%$ with the mechanism version 1.3 in the same temperature range when no pressure increase is assumed. Considering a pressure increase of $4 \% / \mathrm{ms}$, the averaged deviation is reduced to $12 \%$ and $24 \%$ using AramcoMech 3.0 and AramcoMech 1.3, respectively.

\subsection{Effect of $n$-Heptane}

For investigating the n-heptane influence on the IDT, comparative experiments are taken out with a consistent gas mixture with $95 \mathrm{~mol} \%$ methane, $5 \mathrm{~mol} \%$ propane, and an air-fuel ratio of 1.9. For easier comparison, the amount of n-heptane is introduced based on the gas mixture of methane and propane according the formula.

$$
\mathrm{x}_{\mathrm{n}-\mathrm{C}_{7} \mathrm{H}_{16}}=\frac{\left[\mathrm{n}-\mathrm{C}_{7} \mathrm{H}_{16}\right]}{\left[\mathrm{CH}_{4}\right]+\left[\mathrm{C}_{3} \mathrm{H}_{8}\right]}
$$




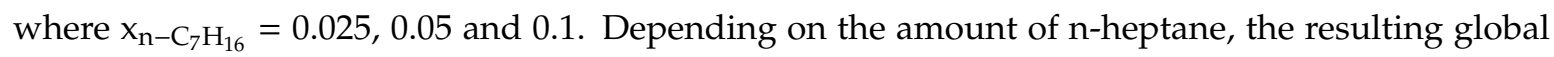
air-fuel ratio $\lambda_{\text {global }}$ changes to $1.685,1.513$ and 1.257 , respectively. In addition, experiments with $100 \mathrm{~mol} \%$ methane and n-heptane addition with $\mathrm{x}_{\mathrm{n}-\mathrm{C}_{7} \mathrm{H}_{16}}=0.1\left(\lambda_{\text {global }}=1.226\right)$ were performed and allowed the comparison of the influence of propane and n-heptane on the IDT (Figures 9-12).

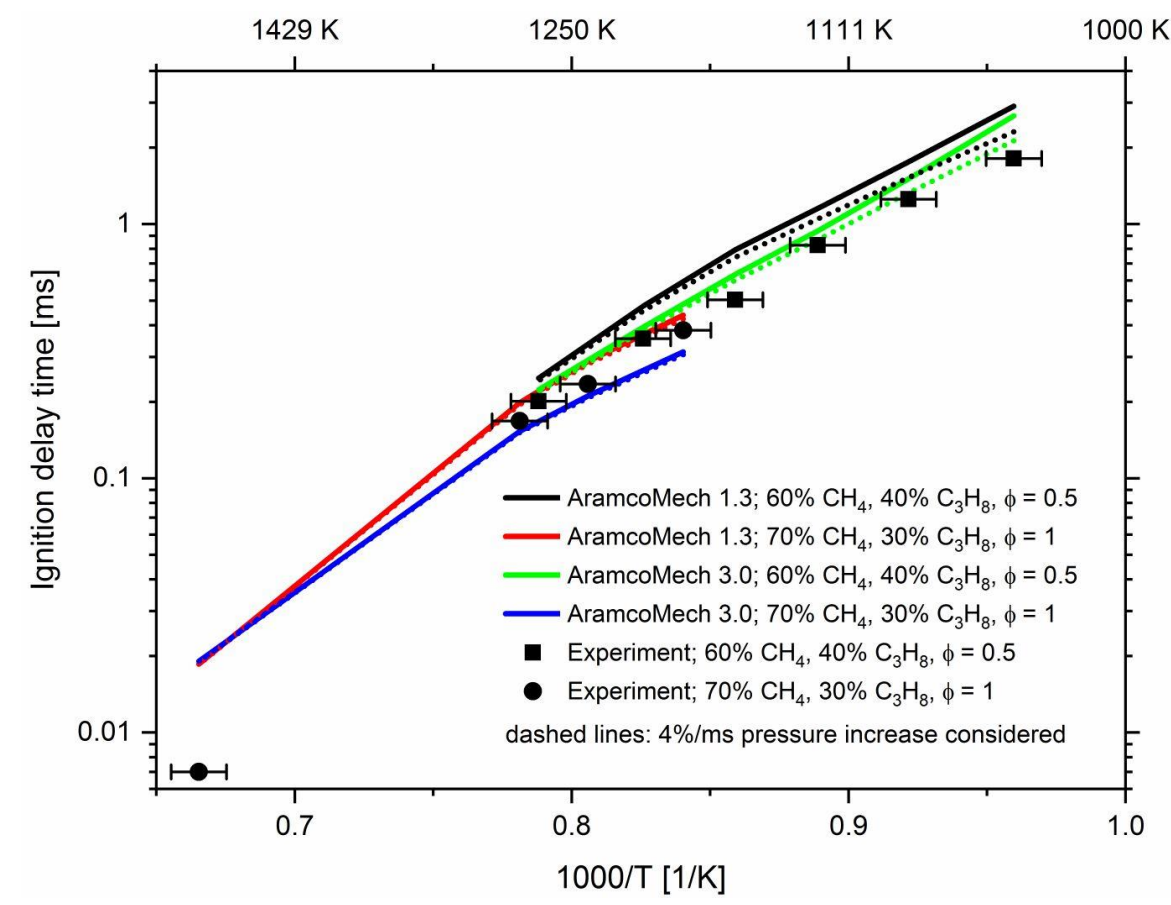

Figure 8. Comparison of calculated IDT considering a pressure increase of $4 \% / \mathrm{ms}$ as well as no increase using the mechanisms AramcoMech 1.3 and 3.0 with experimental ST data published by Petersen et al. [51].

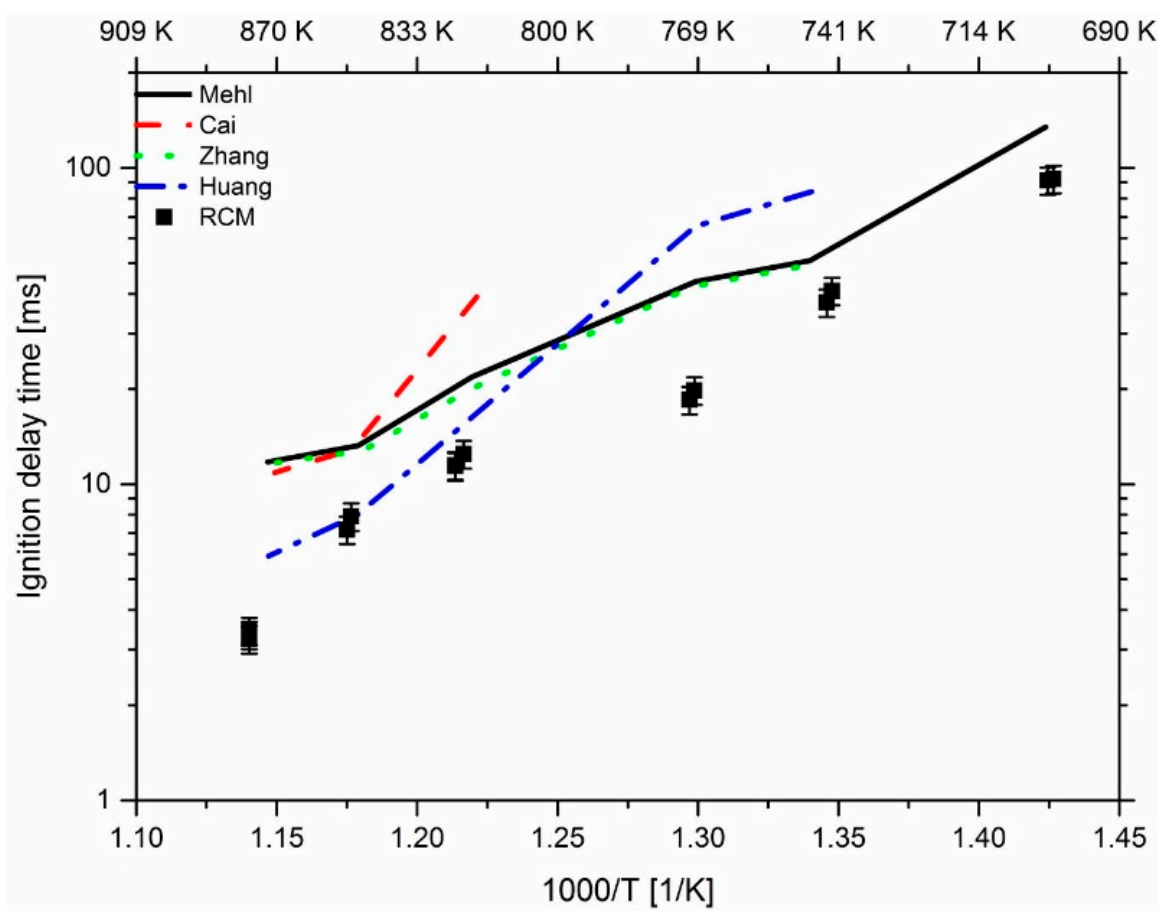

Figure 9. Experimental RCM data (symbols) versus model prediction at $\mathrm{P}_{\mathrm{C}}=60 \mathrm{bar}$ using $95 \mathrm{~mol} \%$

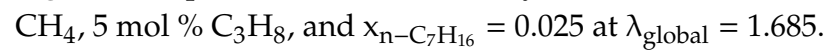




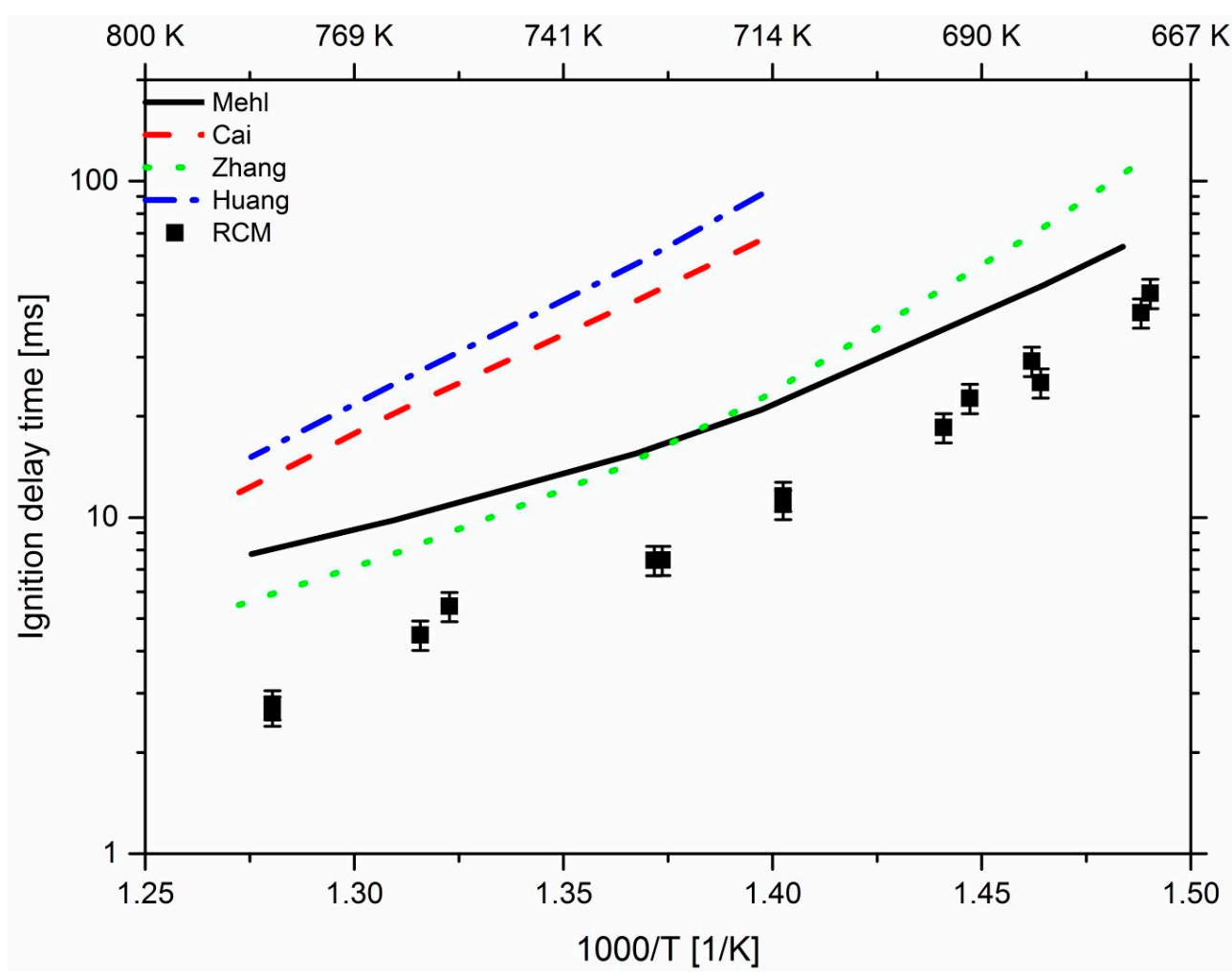

Figure 10. Experimental RCM data (symbols) versus model prediction at $\mathrm{P}_{\mathrm{C}}=60$ bar using $95 \mathrm{~mol} \%$ $\mathrm{CH}_{4}, 5 \mathrm{~mol} \% \mathrm{C}_{3} \mathrm{H}_{8}$, and $\mathrm{x}_{\mathrm{n}-\mathrm{C}_{7} \mathrm{H}_{16}}=0.05$ at $\lambda_{\text {global }}=1.513$.

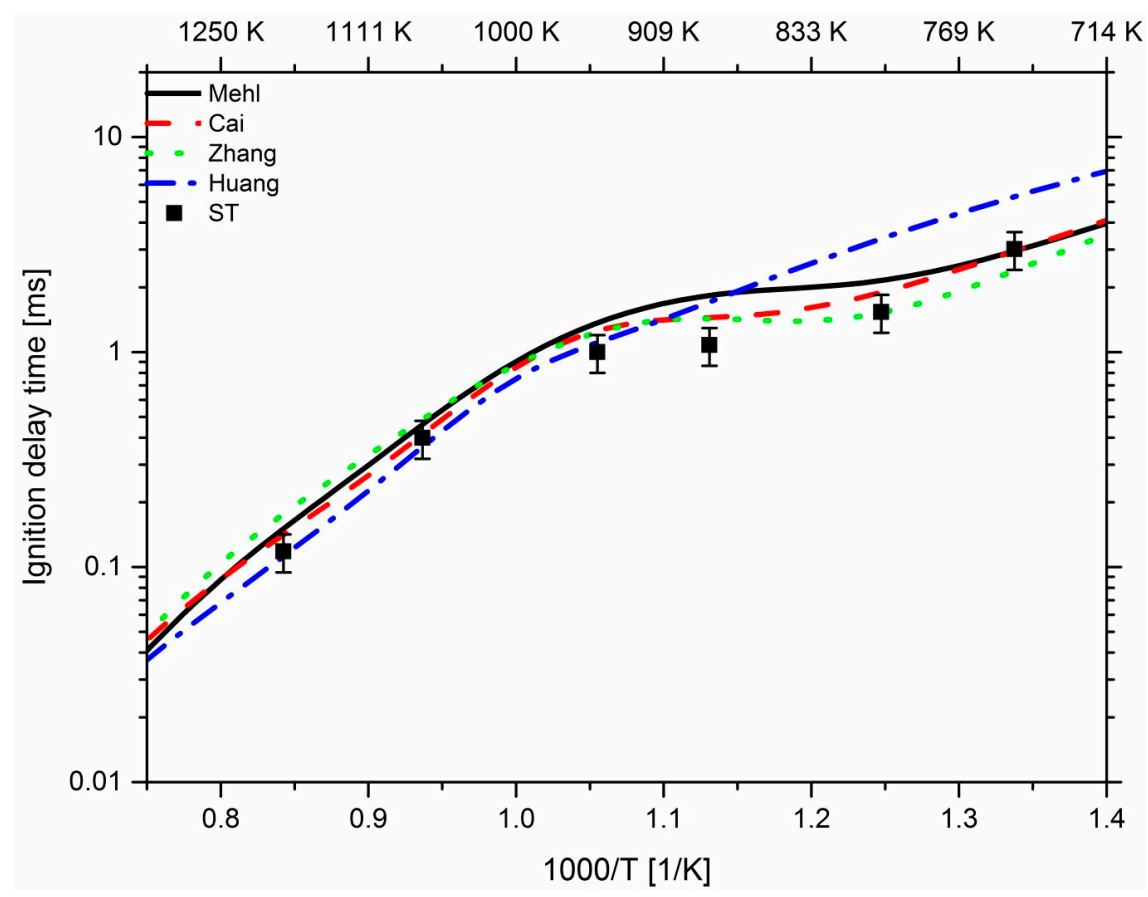

Figure 11. Experimental ST data (symbols) versus model prediction at $\mathrm{P}_{\mathrm{C}}=60$ bar using $95 \mathrm{~mol} \% \mathrm{CH}_{4}$,

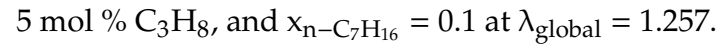

The addition of $n$-heptane to the here used natural gas surrogate mixture, strongly reduces the IDTs compared to the considered pure methane-propane mixtures, in particular at intermediate temperatures. The reducing effect seems much more pronounced compared to the effect of admixing just propane to pure methane. As shown in Figures 11 and 12, in the two ST mixtures no pronouncing 
effect to the reactivity is visible by changing from pure methane to a $95 \mathrm{~mol} \%$ methane- $5 \mathrm{~mol} \%$ propane mixture. It seems that the n-heptane combustion chemistry is controlling the reactivity, even at these small amounts of $n$-heptane addition to the mixtures at small to intermediate temperatures. Comparing the model results to the experimental data, in the case of the smallest addition of n-heptane (see Figure 9), the considered mechanisms tend to overestimate the measured IDTs. Only the mechanism of Huang et al. seems to fit at just one temperature condition, but also shows a wrong behavior in general. Again, with reducing temperature, the mechanism of Cai et al. shows an increasing deviation from the experimental values because of the lacking low temperature branching for propane. This effect decreases with an increasing amount of n-heptane as can be seen in Figures 9-11, when n-heptane chemistry starts to control the reactivity. This is because the mechanism is designed to reflect PRFs and gasoline surrogates, where it works perfectly fine [52]. The IDTs calculated with the mechanism of Zhang et al. and Mehl et al. remain comparable for a temperature above $740 \mathrm{~K}$ with an overestimation of a bit more than $50 \%$ at $750 \mathrm{~K}$ and $70 \%$ at $850 \mathrm{~K}$. The mechanism of Huang et al. shows an increasing overestimation of the IDTs with decreasing temperatures, leading to an IDT-overestimation of about $150 \%$ at $750 \mathrm{~K}$. At a temperature of $700 \mathrm{~K}$, the mechanism of Mehl et al. is the only one whose calculated IDTs are below the maximal computable IDT based on the non-reactive pressure profiles of the RCM with an overestimation of about $50 \%$.

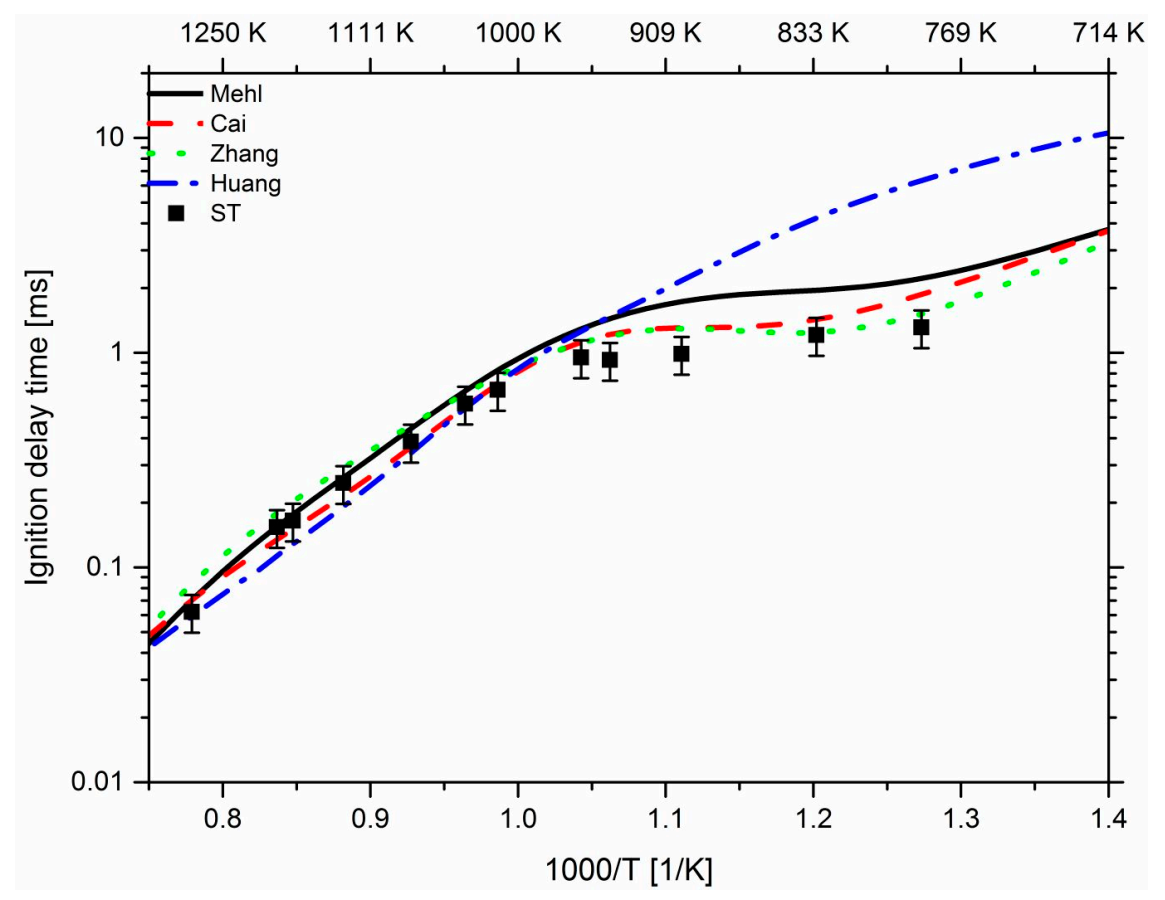

Figure 12. Experimental ST data (symbols) versus model prediction at $\mathrm{P}_{\mathrm{C}}=60$ bar using $100 \mathrm{~mol} \%$ $\mathrm{CH}_{4}$ and $\mathrm{x}_{\mathrm{n}-\mathrm{C}_{7} \mathrm{H}_{16}}=0.1$ at $\lambda_{\text {global }}=1.226$.

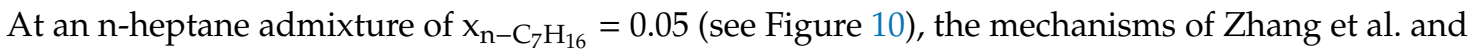
Mehl et al. show the best approximation to the experimentally determined values in the investigated temperature range of 670 to $780 \mathrm{~K}$, with an overestimation between $60 \%$ and $200 \%$. It is furthermore noticeable that although both mechanisms show the tendency to overpredict the experimental IDTs the mechanism of Zhang et al. seems to show the right slope in the results. In comparison, the mechanisms of Cai et al. and Huang et al. show a much higher overestimation, which is above $400 \%$.

The experimental determination of the IDT with the largest addition of $n$-heptane (see Figure 11) is performed in the ST due to the short IDTs. In the temperature range of 950 to $1250 \mathrm{~K}$, all considered mechanisms show a good approximation to the experimentally determined IDTs, whereby the mechanism of Huang can reflect the experimental values accurately. In the temperature range of 840 to $890 \mathrm{~K}$, the mechanism of Zhang et al. shows a decrease in the IDTs with increasing temperature and 
thus predicts a negative temperature coefficient (NTC) behavior, although not clearly evident in the experiments. The mechanisms of Mehl et al. and Cai et al. show a good approximation of the change in reactivity but tend to overestimate the experimental values in this temperature regime. In contrast, in the results of the Huang et al. mechanism, the change in the slope of the IDT curve is only small.

To get more insight into the IDT-reducing effect of the propane and n-heptane admixture, respectively, to methane, the IDT-change by blending methane with $1 \mathrm{~mol} \%$ propane and $1 \mathrm{~mol} \%$ n-heptane, respectively, was calculated. For the simulation, the mechanism of Mehl et al. was used, assuming a gas temperature of $800 \mathrm{~K}$, a pressure of $60 \mathrm{bar}$ and an air-fuel ratio of 1.43 . As shown in the upper part of Figure 13, an admixture of $1 \mathrm{~mol} \%$ of propane leads to an IDT reduction of approximately $40 \%$. The IDT (the point of steep rise of temperature) is reduced by about $77 \%$ when adding $1 \mathrm{~mol} \%$ $\mathrm{n}$-heptane to the methane-air mixture. In addition, the development of the species formaldehyde $\left(\mathrm{CH}_{2} \mathrm{O}\right)$, hydrogen peroxide $\left(\mathrm{H}_{2} \mathrm{O}_{2}\right)$ and hydroperoxyl radicals $\left(\mathrm{HO}_{2}\right)$ is presented in Figure 13 for the three cases. Qualitatively, all three cases show similar trends in these species, which indicates the transition phase until ignition [53], relative to the related IDT. It is commonly known that the decomposition of hydrogen peroxide leads to a strong accumulation of $\mathrm{OH}$ radicals, which subsequently causes the ignition. This trend is also visible in the simulated results. The lower part of Figure 13 shows the development of the species $\mathrm{CH}_{2} \mathrm{O}, \mathrm{H}_{2} \mathrm{O}_{2}$ and $\mathrm{HO}_{2}$ as a function of the time normalized to the IDT. This representation allows the direct comparison of the species concentrations shortly before ignition for pure methane, methane with propane admixture and methane with n-heptane admixture, and only minor differences in the profiles are visible.
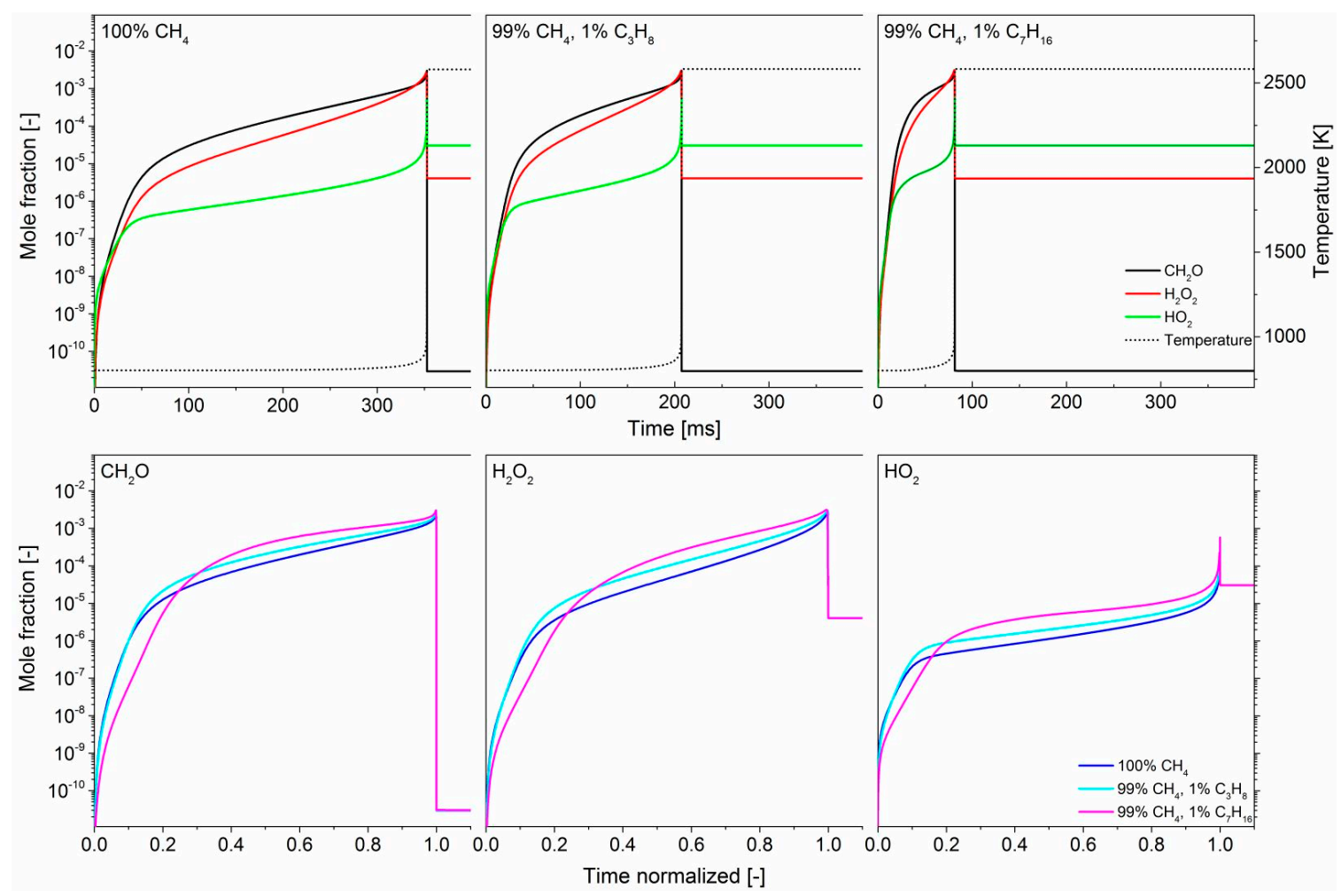

Figure 13. Development of the species formaldehyde $\left(\mathrm{CH}_{2} \mathrm{O}\right)$, hydrogen peroxide $\left(\mathrm{H}_{2} \mathrm{O}_{2}\right)$ and hydroperoxyl radicals $\left(\mathrm{HO}_{2}\right)$ prior to ignition for a methane-air mixture (top, left), methane-air mixture with $1 \mathrm{~mol} \%$ propane addition (top, middle) and methane-air mixture with $1 \mathrm{~mol} \% \mathrm{n}$-heptane addition (top, right). The lower part of this figure shows the species development as a function of the time normalized to the IDT. The simulations were performed at $800 \mathrm{~K}$ gas temperature, $\lambda=1.43$ and a pressure of 60 bar using the mechanism of Mehl et al. 
In order to compare the IDTs of the mixtures with different n-heptane content (Figures 9-11) at one single determined temperature value, the IDT can be estimated for a temperature of $770 \mathrm{~K}$ by logarithmic interpolation of the experimental data. The results are shown in Figure 14. By doubling

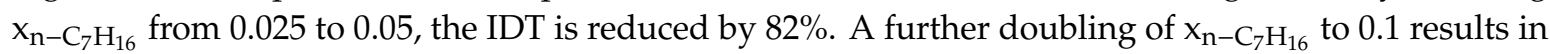
an additional reduction by $34 \%$. However, it has to be taken into account that the addition of n-heptane leads also to a change in the air-fuel ratio. Therefore, the effect of the air-fuel ratio change to the IDT is discussed in more detail in the following section.

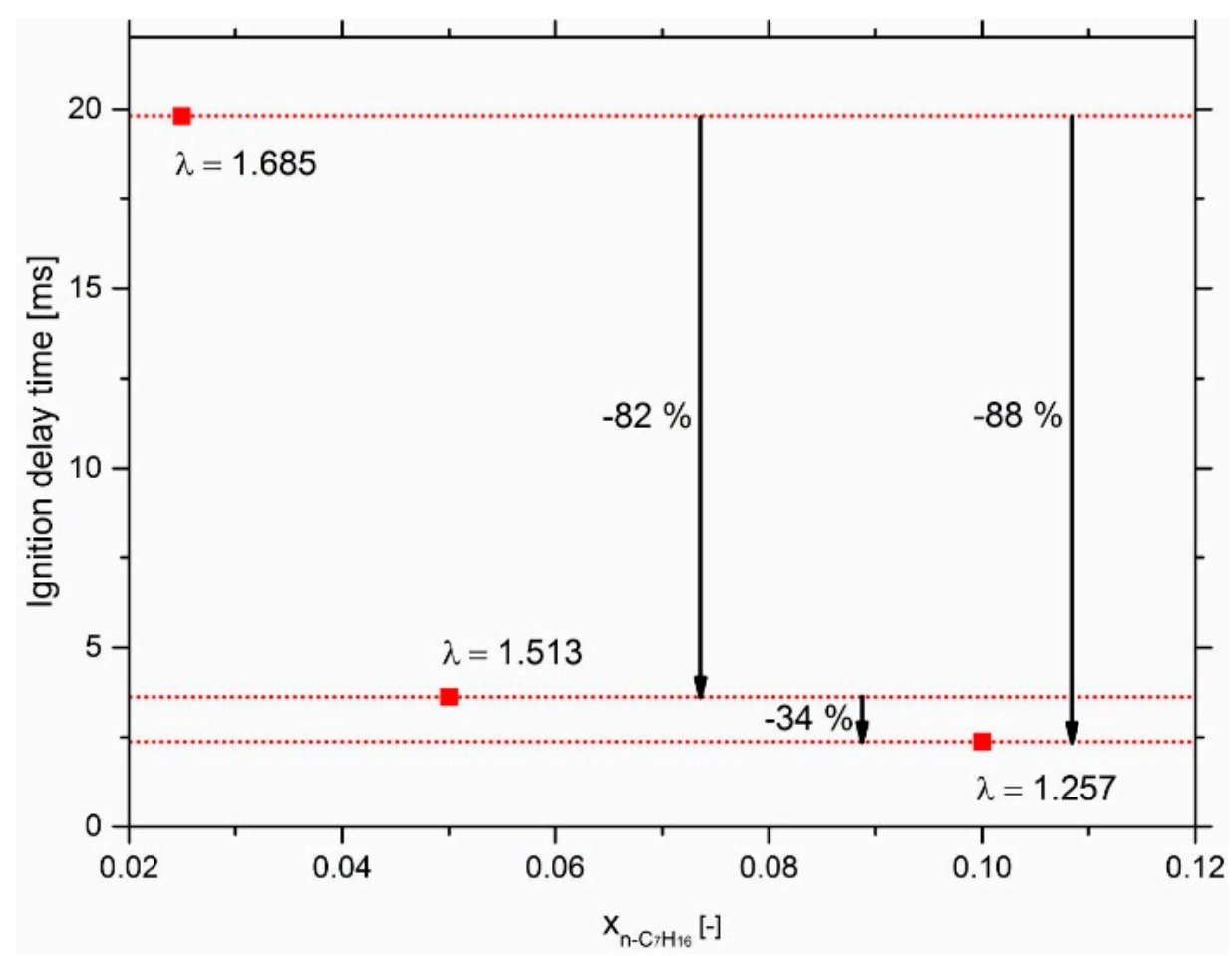

Figure 14. Interpolated IDT of a gas mixture consisting of $95 \mathrm{~mol} \% \mathrm{CH}_{4}, 5 \mathrm{~mol} \% \mathrm{C}_{3} \mathrm{H}_{8}$, and various

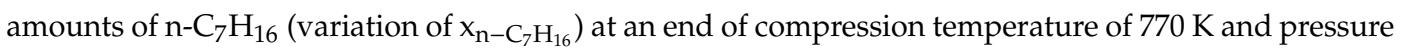
of 60 bar.

For this, the IDTs of the considered three n-heptane admixtures are simulated at an air-fuel ratio of 1.257, 1.513 and 1.685 using the mechanism of Mehl et al. It is shown in Figure 15 that the total change in the IDT gets larger with increasing air-fuel ratio when changing the n-heptane content. Since facility effects could not be considered in this investigation due to the absence of corresponding non-reactive pressure profiles at this particular interpolated condition, a direct comparison of the simulated and measured values is not possible. However, a comparison of relative changes can be made. Considering the relative change of the IDT compared to the effect of the n-heptane amount in the mixture, only a minor effect from the change of the air-fuel ratio is visible in the simulated results. Generally, a doubling of the factor $\mathrm{x}_{\mathrm{n}-\mathrm{C}_{7} \mathrm{H}_{16}}$ leads to a reduction of the IDT by $60 \%$ for all three investigated fuel-air ratios. Further doubling of this factor results in an IDT decrease of approximately $60 \%$ again. This is shown in detail in Figure 15. For a deeper understanding of the individual influence

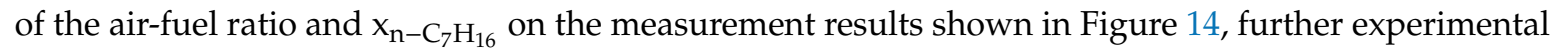
investigations are to be strived for. 


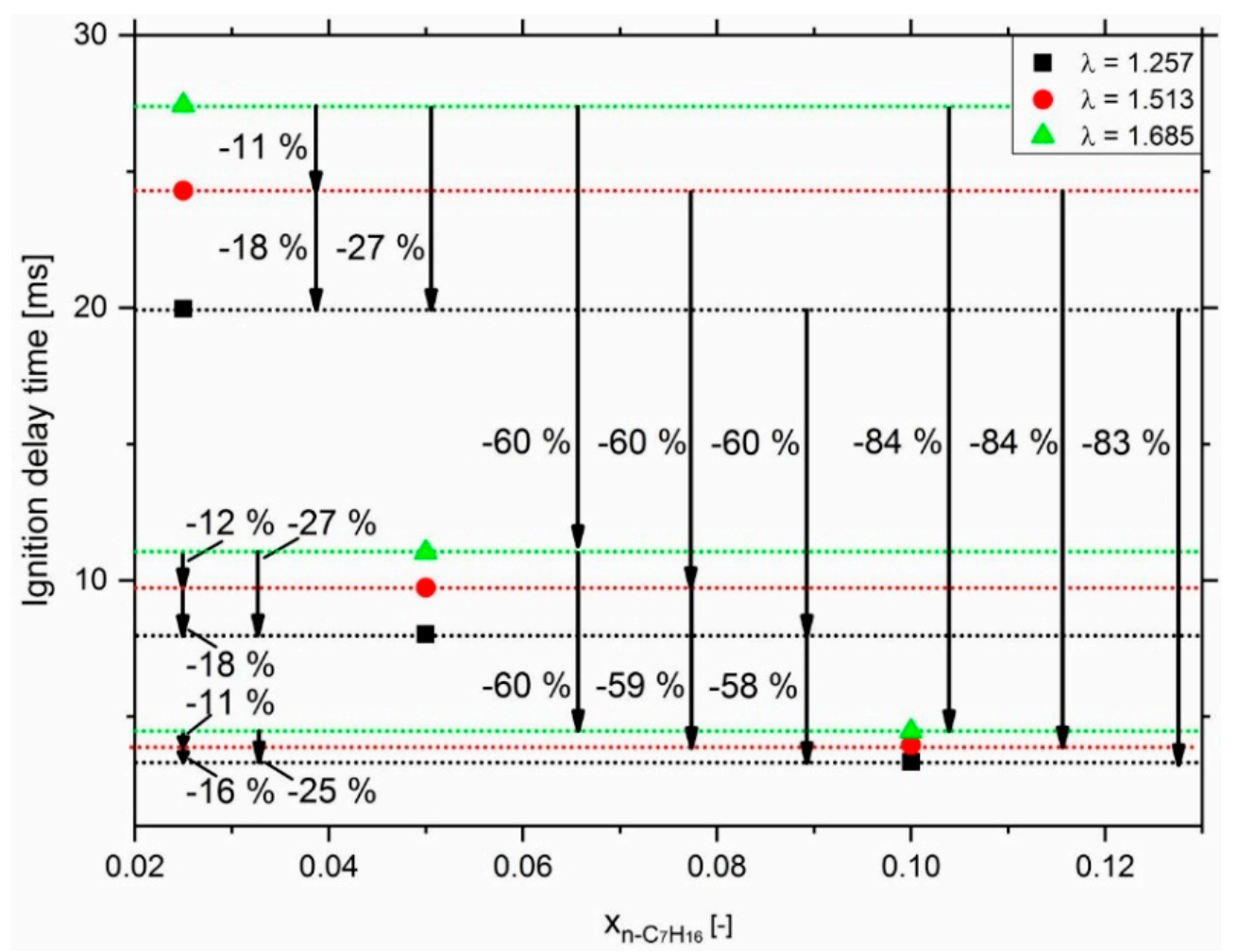

Figure 15. IDT of a gas mixture consisting of $95 \mathrm{~mol}^{\%} \mathrm{CH}_{4}, 5 \mathrm{~mol}^{\%} \mathrm{C}_{3} \mathrm{H}_{8}$, and various amounts of $\mathrm{n}-\mathrm{C}_{7} \mathrm{H}_{16}$, simulated at $770 \mathrm{~K}, 60$ bar and air-fuel ratios of $1.257,1.513$ and 1.685 using the mechanism of Mehl et al.

\subsection{Effect of Pressure}

In order to determine the influence of pressure on the IDTs, the experiments with a gas mixture

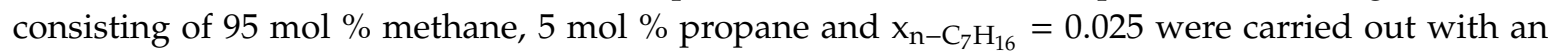
increased end of compression pressure $\mathrm{P}_{\mathrm{c}}$ of 100 bar. Figure 16 shows a comparison of the measurements performed at 60 and 100 bar in the temperature range 700 to $900 \mathrm{~K}$.

The increase in pressure reduces the IDT. This behavior is to be expected, since on the one hand a higher pressure value increases the probability of collisions between reaction partners. On the other hand, the energy released per unit volume increases, which in turn leads to a faster rise of the temperature [54]. Depending on the temperature, the increase in pressure from 60 to 100 bar leads to a reduction in the ignition delay by roughly $70 \%$ at a temperature of $800 \mathrm{~K}$ and to a reduction of approximately $40 \%$ at $700 \mathrm{~K}$. This already includes the effects of changes in the bath gases of the experiments. The comparison between the experimental and simulated data at an end of compression pressure of 60 bar has already been shown in Figure 9. Therefore, just the simulation results at a pressure value of 100 bar are presented along with the experimental data in Figure 16.

As already seen in the simulation results at 60 bar, also at 100 bar, the mechanisms of Mehl et al., Zhang et al. and Huang et al. show similar results at $800 \mathrm{~K}$. As the temperature decreases, the IDT overestimation of Huang et al.'s mechanism increases, leading to an overestimation of more than $200 \%$ at a temperature of around $720 \mathrm{~K}$. The mechanisms of Mehl et al. and Zhang et al. show similar results over the whole investigated temperature range. At $800 \mathrm{~K}$, the measured values are overestimated by a bit more than $110 \%$, and at around $710 \mathrm{~K}$ the overestimation is reduced to a value below $70 \%$. The mechanism of Cai et al. again shows an overestimation of the IDTs well over $400 \%$ in the temperature range, where a calculation was not feasible due to the limitation of the maximal length of the non-reactive pressure traces as discussed above. 


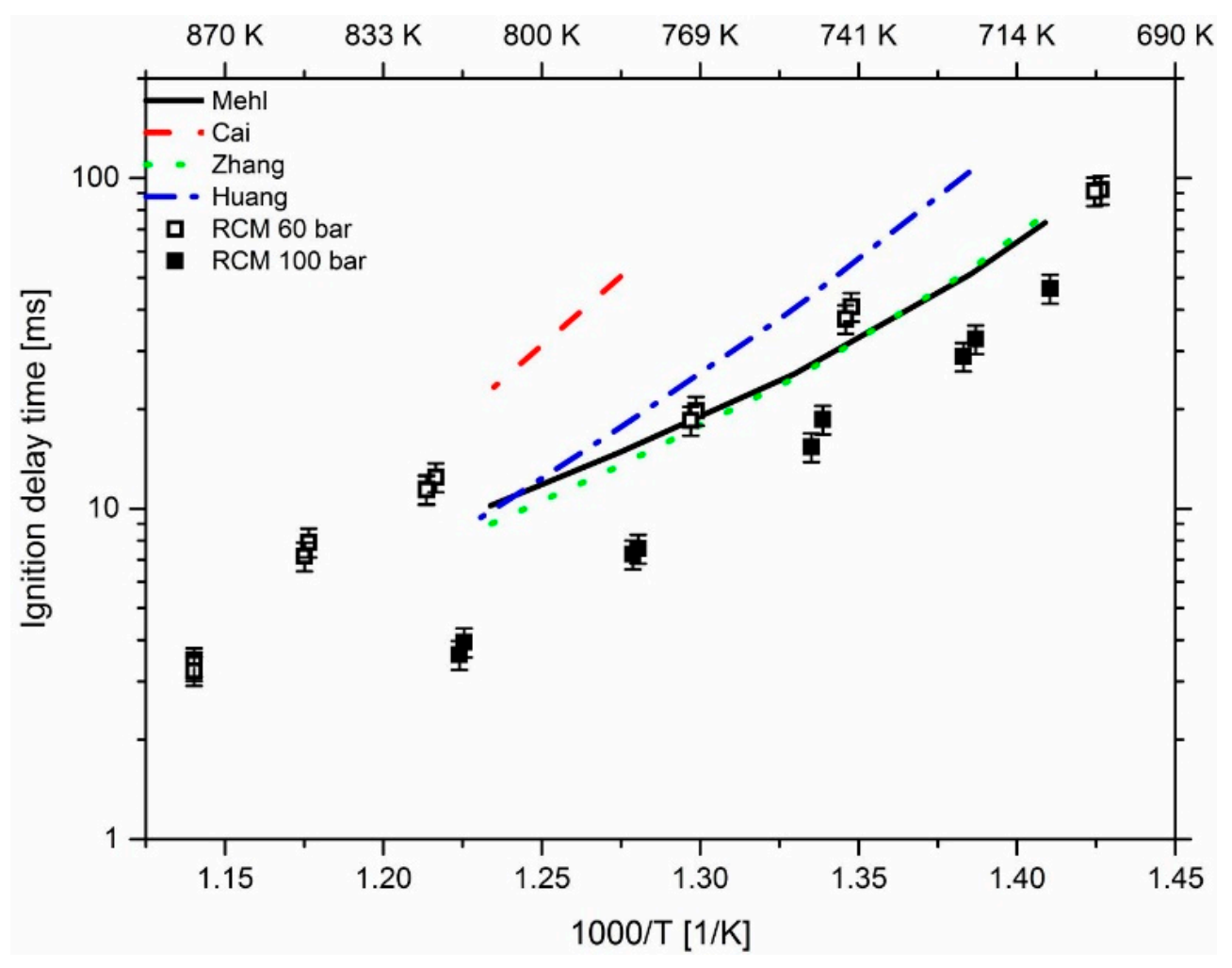

Figure 16. Experimental RCM data at $\mathrm{P}_{\mathrm{c}}=60$ and 100 bar using $95 \mathrm{~mol} \% \mathrm{CH}_{4}, 5 \mathrm{~mol} \% \mathrm{C}_{3} \mathrm{H}_{8}$ and $\mathrm{x}_{\mathrm{n}-\mathrm{C}_{7} \mathrm{H}_{16}}=0.025$ at $\lambda_{\text {global }}=1.685$ versus the model prediction at 100 bar.

\section{Conclusions}

In the presented study, IDT measurements of dual fuel surrogates have been performed in an ST and an RCM at engine relevant conditions. Since in the high-pressure range ( $>50$ bar) hardly any experimental data is available for the validation of simulated IDTs, experiments for the determination of the IDTs of various gas mixtures were carried out. Experiments have been performed in the pressure range of 60 to 100 bar with air-fuel ratios between 1.226 and 1.9. The end of compression temperature ranged from 671 to $1284 \mathrm{~K}$ over both facilities. In addition, various reaction mechanisms were investigated with regard to their suitability for the calculation of ignition processes, as they occur in engines in dual fuel operation mode. Fuels typically used in such engines are diesel and natural gas. Surrogate fuels were defined for a better basis of investigation. Here, n-heptane served as a diesel substitute and a mixture of methane and propane was used as a natural gas surrogate. The investigated mechanisms were the C1-C4 species reaction mechanisms AramcoMech 1.3 [30], 2.0 [24] and 3.0 [34], and the n-heptane mechanisms of Mehl et al. [17], Cai et al. [18], Zhang et al. [23] and Huang et al. [14]. Comparing the simulation results with the experimental data, the following factors were investigated more closely concerning their influence on the IDT: Propane addition to methane, $\mathrm{n}$-heptane addition to methane-propane mixtures and the variation of the end of compression pressures.

In the experimental results, in general an addition of propane or $n$-heptane to the methane mixtures leads to an increase in reactivity at low to intermediate temperatures, due to the low temperature branching of the longer alkanes. The effect of enhancement of reactivity is more pronounced for the addition of $n$-heptane compared to propane. The n-heptane chemistry already dominates for comparable small amounts of the reactivity, making the enhancing effect from further propane addition negligible, as was seen in the ST IDTs.

In the mechanism benchmark, the mechanisms AramcoMech 1.3 and 3.0 showed on average the smallest deviation from the experimental data. In the calculation of the IDTs of pure 
methane, the mechanism of Zhang was best reproducing the experimental values of all investigated n-heptane mechanisms.

When n-heptane is added to the methane-propane mixture, the mechanisms of Mehl et al. and Zhang et al. showed similar results over a wide temperature range with a general overestimation of the IDTs. The mechanism of Cai et al. reproduces the experimental IDTs at high temperatures $(>1000 \mathrm{~K})$ and largest investigated n-heptane addition. However, as the n-heptane addition and the temperature were reduced, a strongly increasing deviation could be observed because of the lacking low temperature branching of the propane sub-chemistry in the mechanism.

At high temperatures and the highest investigated n-heptane admixture, Huang et al.'s mechanism is able to reflect the experimental values accurately. However, the change of reactivity in the ST results is underestimated by Huang et al. mechanism. In contrast to that, the mechanism of Zhang et al. predicts a slight NTC phenomenon although not clearly visible in the experimental data.

The increase in pressure to 100 bar results in a reduction of the IDT. This trend is reproduced correctly by all mechanisms. Within the comparison of the different mechanisms, the mechanisms of Mehl et al. and Zhang et al. showed the best approximation to the experimental values in the investigated temperature range. However, none of the tested mechanisms were able to reasonably reproduce the measured IDTs at all considered conditions. For a suitable detailed kinetic model for the dual fuel engine concept an urgent detailed review of the mechanisms is necessary.

Supplementary Materials: The following are available online at http://www.mdpi.com/1996-1073/12/18/3410/s1. RCM non-reactive pressure traces (ZIP), Experimental IDT results (XLSX).

Author Contributions: Conceptualization, S.S., K.A.H. and F.W.; data curation, S.S.; formal analysis, S.S., A.K.R. and H.M.; investigation, S.S., A.K.R., H.M. and K.A.H.; methodology, S.S., A.K.R., H.M., K.A.H. and F.W.; resources, S.S., A.K.R., H.M., K.A.H. and F.W.; software, S.S.; supervision, K.A.H. and F.W.; validation, S.S.; visualization, S.S.; writing-original draft, S.S., A.K.R. and H.M.; writing-review and editing, S.S., A.K.R., H.M., K.A.H. and F.W.

Funding: This research was funded by the Austrian Research Promotion Agency (FFG), grant number 850690.

Acknowledgments: We would like to show our gratitude to LOGE AB for providing the simulation software LOGEresearch. Open Access Funding by TU Wien.

Conflicts of Interest: The authors declare no conflict of interest.

\section{References}

1. Wright, G. Fundamentals of Medium/Heavy Duty Diesel Engines; Jones \& bartlett Learning: Burlington, MA, USA, 2015.

2. Dietsche, K.-H.; Reif, K. Kraftfahrtechnisches Taschenbuch; 28., überarb. u. erw. Aufl. 2014 ed.; Springer Vieweg: Wiesbaden, Germany, 2014.

3. Schlick, H. Potentials and challenges of gas and dual-fuel engines for marine application. In Proceedings of the 5th Cimac Cascades, Busan, Korea, 23 October 2014.

4. Fischer, M. Modellierung der Multikomponenten-Verdampfung im Homogenisierten Dieselmotorischen Brennverfahren; Cuvillier Verlag Göttingen: Göttingen, Germany, 2006; Volume 1.

5. Jing, B.; Wandel, A.P. Numerical investigation into natural gas-diesel dual-fuel engine configuration. In Proceedings of the 11th Asia-Pacific Conference on Combustion, ASPACC 2017, Sydney, Australia, 10-14 December 2017.

6. Li, Y.; Li, H.; Guo, H.; Li, Y.; Yao, M. A numerical investigation on methane combustion and emissions from a natural gas-diesel dual fuel engine using CFD model. Appl. Energy 2017, 205, 153-162. [CrossRef]

7. Zhao, W.; Yang, W.; Fan, L.; Zhou, D.; Ma, X. Development of a skeletal mechanism for heavy-duty engines fuelled by diesel and natural gas. Appl. Therm. Eng. 2017, 123, 1060-1071. [CrossRef]

8. Ra, Y.; Chuahy, F.; Kokjohn, S. Development and validation of a reduced reaction mechanism with a focus on diesel fuel/syngas co-oxidation. Fuel 2016, 185, 663-683. [CrossRef]

9. Eder, L.; Ban, M.; Pirker, G.; Vujanovic, M.; Priesching, P.; Wimmer, A. Development and Validation of 3D-CFD Injection and Combustion Models for Dual Fuel Combustion in Diesel Ignited Large Gas Engines. Energies 2018, 11, 643. [CrossRef] 
10. Mansor, W.N.W.; Olsen, D.B. Computational modeling of diesel and dual fuel combustion using CONVERGE CFD software. ARPN J. Eng. Appl. Sci. 2016, 11, 13697-13707.

11. Hockett, A.G.; Hampson, G.; Marchese, A.J. Natural gas-diesel RCCI CFD simulations using multi-component fuel surrogates. Int. J. Powertrains 2017, 6, 76-108. [CrossRef]

12. Ritzke, J.; Andree, S.; Theile, M.; Henke, B.; Schleef, K.; Nocke, J.; Hassel, E. Simulation of a Dual-Fuel Large Marine Engines using combined 0/1-D and 3-D Approaches. In Proceedings of the CIMAC Congress, Helsinki, Finland, 6-10 June 2016.

13. Hockett, A.; Hampson, G.; Marchese, A.J. Development and Validation of a Reduced Chemical Kinetic Mechanism for Computational Fluid Dynamics Simulations of Natural Gas/Diesel Dual-Fuel Engines. Energy Fuels 2016, 30, 2414-2427. [CrossRef]

14. Huang, H.; Lv, D.; Zhu, J.; Zhu, Z.; Chen, Y.; Pan, Y.; Pan, M. Development of a new reduced diesel/natural gas mechanism for dual-fuel engine combustion and emission prediction. Fuel 2019, 236, 30-42. [CrossRef]

15. Bierschenk, D.M.; Pillai, M.R.; Lin, Y.; barnett, S.A. Effect of Ethane and Propane in Simulated Natural Gas on the Operation of Ni-YSZ Anode Supported Solid Oxide Fuel Cells. Fuel Cells 2010, 10, 1129-1134. [CrossRef]

16. Healy, D.; Curran, H.J.; Simmie, J.M.; Kalitan, D.M.; Zinner, C.M.; barrett, A.B.; Petersen, E.L.; Bourque, G. Methane/ethane/propane mixture oxidation at high pressures and at high, intermediate and low temperatures. Combust. Flame 2008, 155, 441-448. [CrossRef]

17. Mehl, M.; Pitz, W.J.; Westbrook, C.K.; Curran, H.J. Kinetic modeling of gasoline surrogate components and mixtures under engine conditions. Proc. Combust. Inst. 2011, 33, 193-200. [CrossRef]

18. Cai, L.; Pitsch, H. Optimized chemical mechanism for combustion of gasoline surrogate fuels. Combust. Flame 2015, 162, 1623-1637. [CrossRef]

19. Curran, H.J.; Gaffuri, P.; Pitz, W.J.; Westbrook, C.K. A comprehensive modeling study of iso-octane oxidation. Combust. Flame 2002, 129, 253-280. [CrossRef]

20. Narayanaswamy, K.; Blanquart, G.; Pitsch, H. A consistent chemical mechanism for oxidation of substituted aromatic species. Combust. Flame 2010, 157, 1879-1898. [CrossRef]

21. Li, J.; Kazakov, A.; Dryer, F.L. Experimental and numerical studies of ethanol decomposition reactions. J. Phys. Chem. A 2004, 108, 7671-7680. [CrossRef]

22. Lamoureux, N.; Desgroux, P.; El Bakali, A.; Pauwels, J.F. Experimental and numerical study of the role of $\mathrm{NCN}$ in prompt-NO formation in low-pressure CH4-O2-N2 and $\mathrm{C} 2 \mathrm{H} 2-\mathrm{O} 2-\mathrm{N} 2$ flames. Combust. Flame 2010, 157, 1929-1941. [CrossRef]

23. Zhang, K.; Banyon, C.; Bugler, J.; Curran, H.J.; Rodriguez, A.; Herbinet, O.; Battin-Leclerc, F.; B'Chir, C.; Heufer, K.A. An updated experimental and kinetic modeling study of n-heptane oxidation. Combust. Flame 2016, 172, 116-135. [CrossRef]

24. Li, Y.; Zhou, C.-W.; Somers, K.P.; Zhang, K.; Curran, H.J. The oxidation of 2-butene: A high pressure ignition delay, kinetic modeling study and reactivity comparison with isobutene and 1-butene. Proc. Combust. Inst. 2017, 36, 403-411. [CrossRef]

25. Bugler, J.; Somers, K.P.; Silke, E.J.; Curran, H.J. Revisiting the Kinetics and Thermodynamics of the Low-Temperature Oxidation Pathways of Alkanes: A Case Study of the Three Pentane Isomers. J. Phys. Chem. A 2015, 119, 7510-7527. [CrossRef]

26. Zhang, K.; Banyon, C.; Togbé, C.; Dagaut, P.; Bugler, J.; Curran, H.J. An experimental and kinetic modeling study of n-hexane oxidation. Combust. Flame 2015, 162, 4194-4207. [CrossRef]

27. Bugler, J.; Marks, B.; Mathieu, O.; Archuleta, R.; Camou, A.; Grégoire, C.; Heufer, K.A.; Petersen, E.L.; Curran, H.J. An ignition delay time and chemical kinetic modeling study of the pentane isomers. Combust. Flame 2016, 163, 138-156. [CrossRef]

28. Wang, H.; Yao, M.; Reitz, R.D. Development of a Reduced Primary Reference Fuel Mechanism for Internal Combustion Engine Combustion Simulations. Energy Fuels 2013, 27, 7843-7853. [CrossRef]

29. Darcy, D.; Mehl, M.; Simmie, J.M.; Würmel, J.; Metcalfe, W.K.; Westbrook, C.K.; Pitz, W.J.; Curran, H.J. An experimental and modeling study of the shock tube ignition of a mixture of n-heptane and n-propylbenzene as a surrogate for a large alkyl benzene. Proc. Combust. Inst. 2013, 34, 411-418. [CrossRef]

30. Metcalfe, W.K.; Burke, S.M.; Ahmed, S.S.; Curran, H.J. A Hierarchical and Comparative Kinetic Modeling Study of C1-C2 Hydrocarbon and Oxygenated Fuels. Int. J. Chem. Kinet. 2013, 45, 638-675. [CrossRef]

31. Healy, D.; Kalitan, D.M.; Aul, C.J.; Petersen, E.L.; Bourque, G.; Curran, H.J. Oxidation of C1-C5 Alkane Quinternary Natural Gas Mixtures at High Pressures. Energy Fuels 2010, 24, 1521-1528. [CrossRef] 
32. Wang, H.; Yao, M.; Yue, Z.; Jia, M.; Reitz, R.D. A reduced toluene reference fuel chemical kinetic mechanism for combustion and polycyclic-aromatic hydrocarbon predictions. Combust. Flame 2015, 162, 2390-2404. [CrossRef]

33. Sun, Y.; Reitz, R.D. Modeling Diesel Engine NOx and Soot Reduction with Optimized Two-Stage Combustion; SAE International in United States: Warrendale, PA, USA, 2006. [CrossRef]

34. Zhou, C.-W.; Li, Y.; Burke, U.; Banyon, C.; Somers, K.P.; Ding, S.; Khan, S.; Hargis, J.W.; Sikes, T.; Mathieu, O.; et al. An experimental and chemical kinetic modeling study of 1,3-butadiene combustion: Ignition delay time and laminar flame speed measurements. Combust. Flame 2018, 197, 423-438. [CrossRef]

35. LOGEsoft. Available online: http://www.logesoft.com (accessed on 16 May 2019).

36. Tänzler, A.G. Experimentelle Untersuchung eines Dual-Fuel-Brennverfahrens für schwere Nutzfahrzeugmotoren; Springer Fachmedien: Wiesbaden, Germany, 2017. [CrossRef]

37. Pachler, R.F.; Ramalingam, A.K.; Heufer, K.A.; Winter, F. Reduction and validation of a chemical kinetic mechanism including necessity analysis and investigation of $\mathrm{CH} 4 / \mathrm{C} 3 \mathrm{H} 8$ oxidation at pressures up to 120 bar using a rapid compression machine. Fuel 2016, 172, 139-145. [CrossRef]

38. Burke, U.; Beeckmann, J.; Kopp, W.A.; Uygun, Y.; Olivier, H.; Leonhard, K.; Pitsch, H.; Heufer, K.A. A comprehensive experimental and kinetic modeling study of butanone. Combust. Flame 2016, 168, $296-309$. [CrossRef]

39. Lee, C.; Vranckx, S.; Heufer, K.A.; Khomik, S.V.; Uygun, Y.; Olivier, H.; Fernandez, R.X. On the Chemical Kinetics of Ethanol Oxidation: Shock Tube, Rapid Compression Machine and Detailed Modeling Study. Z. Für Phys. Chem. 2012, 226, 1-28. [CrossRef]

40. Ramalingam, A.; Zhang, K.; Dhongde, A.; Virnich, L.; Sankhla, H.; Curran, H.; Heufer, K.A. An RCM experimental and modeling study on $\mathrm{CH} 4$ and $\mathrm{CH} 4 / \mathrm{C} 2 \mathrm{H} 6$ oxidation at pressures up to 160 bar. Fuel 2017, 206, 325-333. [CrossRef]

41. Morley, C. Gaseq-A Chemical Equilibrium Program for Windows. Available online: http://www.gaseq.co.uk/ (accessed on 29 September 2017).

42. Shock \& Detonation Toolbox - Cantera 2.1. Available online: http://shepherd.caltech.edu/EDL/public/cantera/ html/SD_Toolbox/ (accessed on 29 September 2017).

43. Goodwin, D.G.; Moffat, H.K.; Speth, R.L. Cantera: An Object-Oriented Software Toolkit for Chemical Kinetics, Thermodynamics, and Transport Processes; Version 2.2. 1; Cantera Developers: Warrenville, IL, USA, 2016.

44. Minwegen, H.; Burke, U.; Heufer, K.A. An experimental and theoretical comparison of C3-C5 linear ketones. Proc. Combust. Inst. 2017, 36, 561-568. [CrossRef]

45. Burke, S.M.; Burke, U.; Mc Donagh, R.; Mathieu, O.; Osorio, I.; Keesee, C.; Morones, A.; Petersen, E.L.; Wang, W.; DeVerter, T.A.; et al. An experimental and modeling study of propene oxidation. Part 2: Ignition delay time and flame speed measurements. Combust. Flame 2015, 162, 296-314. [CrossRef]

46. Sung, C.-J.; Curran, H.J. Using rapid compression machines for chemical kinetics studies. Prog. Energy Combust. Sci. 2014, 44, 1-18. [CrossRef]

47. Petersen, E.L.; Hanson, R.K. Nonideal effects behind reflected shock waves in a high-pressure shock tube. Shock Waves 2001, 10, 405-420. [CrossRef]

48. Heufer, K.A.; Olivier, H. Determination of ignition delay times of different hydrocarbons in a new high pressure shock tube. Shock Waves 2010, 20, 307-316. [CrossRef]

49. Schuh, S.; Winter, F. Comparing the Influence of Propane and n-Heptane Addition on Methane Ignition. In Proceedings of the 8th European Combustion Meeting, Dubrovnik, Croatia, 18-21 April 2017.

50. Cord, M.; Husson, B.; Lizardo Huerta, J.C.; Herbinet, O.; Glaude, P.A.; Fournet, R.; Sirjean, B.; Battin-Leclerc, F.; Ruiz-Lopez, M.; Wang, Z.; et al. Study of the low temperature oxidation of propane. J. Phys. Chem. A 2012, 116, 12214-12228. [CrossRef]

51. Petersen, E.L.; Kalitan, D.M.; Simmons, S.; Bourque, G.; Curran, H.J.; Simmie, J.M. Methane/propane oxidation at high pressures: Experimental and detailed chemical kinetic modeling. Proc. Combust. Inst. 2007, 31, 447-454. [CrossRef]

52. Cai, L.; Ramalingam, A.; Minwegen, H.; Heufer, K.A.; Pitsch, H. Impact of exhaust gas recirculation on ignition delay times of gasoline fuel: An experimental and modeling study. Proc. Combust. Inst. 2019, 37, 639-647. [CrossRef] 
53. Schiffner, M.; Jud, M.; Sattelmayer, T. Reaction Kinetics Analysis of Dual Fuel Internal Combustion Engines Based on Ignition Delay Times Using n-Heptane/Methane Fuel Blends. In Proceedings of the 8th European Combustion Meeting, Dubrovnik, Croatia, 18-21 April 2017.

54. Steen, H. Handbuch des Explosionsschutzes; Wiley-VCH: Weinheim, Germany, 2000.

(C) 2019 by the authors. Licensee MDPI, Basel, Switzerland. This article is an open access article distributed under the terms and conditions of the Creative Commons Attribution (CC BY) license (http://creativecommons.org/licenses/by/4.0/). 